\title{
EFFICIENT PROCESS OR "CHILLING EFFECTS"? TAKEDOWN NOTICES UNDER SECTION 512 OF THE DIGITAL MILLENNIUM COPYRIGHT ACT
}

\author{
Jennifer M. Urban \& Laura Quilter $\dagger$
}

\section{INTRODUCTION}

The Online Copyright Infringement Liability Limitation Act (OCILLA), codified at 17 USCA $\S 512,1$ was passed in 1998 as a compromise between the nation's copyright and online service provider (OSP) ${ }^{2}$ industries. ${ }^{3}$ The legislation, passed as Title II of the

$\dagger$ Jennifer Urban, Clinical Associate Professor of Law, University of Southem California School of Law. Laura Quilter, Non-Resident Fellow at the Samuelson Law, Technology \& Public Policy Clinic, UC Berkeley Boalt Hall School of Law (during the time of this paper). This Article is possible only because of the contributions of many. We are grateful to Google Inc., The Planet, the Internet Archive, and all the individual contributors of notices to Chilling Effects and thus, our data set. Thank you to Wendy Seltzer for all the work coding and maintaining the back-end database, and expert advice all along. We thank Deirdre Mulligan, James Spindler, and all the participants at the Santa Clara High Tech Law Journal Conference, for their many valuable comments. Conference on Third Party Liability in Intellectual Property Law, Oct. 7, 2005. We are grateful to the Samuelson Law, Technology \& Public Policy Clinic, Cy Pres grant funds in Supnick v. Amazon.com, the Glushko-Samuelson Foundation, and the Kahle/Austin Foundation for financial support of this research. Last, but most definitely not least, we thank the excellent law student researchers from Boalt and USC who spent many hours coding each notice in our database: Brent Tubbs and Jerry Vathielel (Summer 2005), and Christine Hopkins and Raechel Groom (2003-04). Christine Kawasaki provided valuable research assistance. A special note of thanks belongs to Christine Hopkins, Prof. Urban's excellent research assistant, who took the lead in the coding effort, was tireless in researching the background of Section 512, and who worked directly on early drafts of the background section. And, thank you to Bruce Nash for database support.

1. OCILLA is codified as Title II of the Digital Millennium Copyright Act at 17 U.S.C. $\S 512(2000)$.

2. We generally use the term "OSP" to reflect any online service provider covered by $\S 512$, modifying it with the appropriate section. This helps to avoid confusion with the term "ISP" which is often, but not always, used more narrowly to describe $\$$ 512(a) (Internet access) providers.

3. Senator Hatch lauded the private sector for their compromises which made the unanimous passage of the bill in the Senate possible. See 144 CONG. REC. S12375-02, S12376. 
Digital Millennium Copyright Act, ${ }^{4}$ created a process that was intended to help copyright owners ensure rapid removal of allegedly infringing material from the Internet while guaranteeing compliant OSPs a safe harbor from liability for Internet users' acts of copyright infringement. The U.S. copyright industry thus gained a new tool to combat the loss of billions of dollars (U.S.) annually from copyright infringement; ${ }^{5}$ OSPs, concerned about the direction of court decisions concerning their liability for their users' copyright infringement, received protection from potential secondary liability. To qualify, OSPs must "accommodate" technical protection measures employed by copyright holders and implement policies for terminating the accounts of repeat infringers. ${ }^{6}$ Further measures are also required of OSPs in some situations, including the takedown of online material in response to a copyright-holder notice-the subject of this Article.

In negotiating the $\S 512$ compromise, copyright holders sought to ensure that OSPs had incentives to remove infringing material, and OSPs sought to avoid lawsuits and judgments based on secondary liability for users' acts of copyright infringement. ${ }^{7}$ The resulting $\S 512$ safe harbor is granted to OSPs in exchange for the "expeditious" takedown, upon notice by the copyright holder, of allegedly infringing material. The alleged infringers are to be protected from mistaken takedowns and misuse of this rather

Industry representatives were able to negotiate the bill amongst themselves from January to April 1998. S. REP. No. 105-109 (1998).

4. The Digital Millennium Copyright Act, H.R. 2281/S.2037, incorporated originally separate proposals for on-line limitation of liability, Senator Ashcroft's S. 1146 and Congressman Coble's H.R. 3209 (introduced the year before as H.R. 2180), with four other titles whose original impetus was updating United States copyright law to match provisions of the WIPO treaty. The WIPO treaty had not included any special provisions concerning the liability of OSPs. S. REP. NO. 105-190 (1998).

5. According to the industry association numbers, which we recognize are not uncontroversial: During the debates on the DMCA, Sen. Kohl cited $\$ 15$ billion in losses, also based on entertainment industry numbers. See generally JESSICA LITMAN, DIGITAL COPYRIGHT: Protecting InTEllectual Property ON THE INTERNET (2000). The RIAA estimates \$4.2 billion/year worldwide. See http://www.riaa.com/issues/piracy/ (last visited Apr. 22, 2006). The MPAA estimates $\$ 3$ billion/year worldwide. See http://www.mpaa.org/anti-piracy/ (last visited Apr. 22, 2006). The Business Software Association (BSA) estimates losses to the software industry of \$31 billion/year worldwide. See 2005 Global Study,

http://www.bsa.org/globalstudy/upload/2005-Global-Study-English.pdf (last visited Apr. 22, 2006).

6. The definition of "repeat infringer" continues to be debated. Some copyright holders press OSPs to terminate users who are the subject of multiple notices. (Confidential Interview with ISP representative.) However, case law has not yet established the parameters of this requirement. A number of courts have discussed termination on receipt of multiple notices as demonstrating effective implementation of a repeat infringer policy. See infra note 19.

7. Rossi v. Motion Picture Ass'n of Am., Inc., 391 F.3d 1000, 1003-04 (9th Cir. 2004). 
remarkable extra-judicial process principally through a counternotice procedure, through which they can demand replacement of the material if the copyright owner fails to initiate a lawsuit.

Copyright-holders have had access to the easy-to-initiate takedown process afforded by 17 U.S.C. $\$ 512$ for nearly eight years, and a review of the law seems in order. Has this compromise between industries worked as planned? Has infringing material been removed from the Internet? How have Internet publishers fared, including businesses large and small, bloggers, critics, and the many other speakers who make use of the Internet? How, if at all, has the great democratization of expression afforded by the Internet been affected by a simple, expedient extra-judicial procedure for removing material? These questions are frustratingly difficult to answer, a difficulty exacerbated by the fact that $\S 512$ takedown notices-a matter of private action like any other cease-and-desist letter-are not part of the public record.

But for nearly four years, the Chilling Effects project has attempted to fill some of the gaps in this knowledge by collecting and archiving cease-and-desist notices of all kinds. Chilling Effects has collected $\S 512$ takedown notices from a variety of sources, including all notices received by Google Inc. For this Article, we analyzed nearly 900 of these notices along various axes in an attempt to begin answering some of these questions. Our research is ongoing, and presumably over time the data set will increase in depth and size. As such, this is a preliminary evaluation. Insofar as we have begun to answer some questions, we have also learned enough to raise more questions and establish directions for further research. Unfortunately, however, our findings comprise a rather negative snapshot of the ways in which the $\S 512$ process is being used, and reveal little benefit to some of the constituencies it was intended to support.

In Part II of this Article, we explain the $\S 512$ process. In Part III, we sketch the rationale and history behind $\S 512$, and briefly note some of the predictions, hopes and concerns that $\S 512$ inspired in industry players, policymakers and commentators. In Parts IV, V, and VI, we present our study of $\S 512$ notices, including a description of the data set, our methodology and findings. In Part VII, we analyze the findings and make some suggestions for change to the safe harbor scheme set up by $\S 512$. 


\section{THE DMCA SECTION 512 PROCESS}

Section 512 creates several categories of protection for OSPs. ${ }^{8}$ The broadest protection, provided by $\S 512(\mathrm{a})$, is a safe harbor for OSPs who provide transmission and routing-for example, broadband, DSL, dial-up, and high-speed Internet access providers. For these types of services, where the OSP is acting as a "mere conduit" through which information flows, there is no requirement that the OSP remove material; the law simply gives them safe harbor from their users' infringements, so long as they adopt a policy for terminating repeat infringers and accommodate standard technical protection measures. ${ }^{9}$ OSPs that cache information to improve network performance are required by $\S 512(\mathrm{~b})$ to respond "expeditiously" to notices of infringement by removing or disabling access to the allegedly infringing material when certain conditions are met and are subject to court-ordered injunctions to remove material. ${ }^{10}$ The material must have been removed or ordered removed from the originating site and the content holder must give such notification to the service provider.

In order to receive safe harbor, hosting services and search engines are required by $\S 512(\mathrm{c})$-(d) to respond "expeditiously" to notices of copyright infringement by removing hosted content, or links to content, when they receive a notice alleging copyright infringement. 11 Section 512(c) applies to hosted content (websites, forums, social networking profiles, and the like), and requires OSPs

8. Section 17 USCA $\S 512(\mathrm{k})(1)$ defines the various service providers.

9. Connectivity services covered by $\S 512$ (a) are subject to court-ordered injunctions to terminate an infringer's access or to block access to specifically identified locations outside the United States.

10. See 17 USCA § 512(b)(2)(E)(i)-(ii).

11. Section 512 (b) requires a notice-and-takedown process for some network providers who cache content for system efficiency. Our data does not contain notices citing $\S 512$ (b) although it does include some sixteen notices citing Google's search index cache. When doing the study, we proceeded on the assumption that Google's cache did not fall under the caching services regulated by $\S 512$ (b), for several reasons: (1) we did not consider the cache to be "intermediate and temporary storage" as defined in $\S 512(\mathrm{~b})(1)$; (2) the storage is not automatically carried out after transmission is requested by a user, but performed automatically at Google's behest, as its spider crawls the web. See Google Web Search Features, http://www.google.com/intl/en/help/features.html\#cached (last visited Mar. 15, 2005); and (3) the Google cache appears to operate regardless of whether subsequent users request information from the original provider. In other words, we understood § 512(b) to apply to an Internet access provider, such as a dial-up or broadband provider, who cached repeatedly requested material to minimize network load and speed transmission. However, two District Courts have just found safe harbor for Google's search engine cache under $\S 512$ (b). Blake A. Field v. Google Inc., NO. CV-S-04-0413-RCJ-LRL, 2006 U.S. Dist. LEXIS 10923 (D. Nev. Jan. 12, 2006), available at http://www.eff.org/IP/blake_v_google/google_nevada_order.pdf . 
to establish and maintain a complicated process. When an OSP receives a statutorily compliant notice, ${ }^{12}$ it must perform the following: 1) take down the material "expeditiously"; 2) notify the alleged infringer that material has been removed; and 3) forward any counternotices from alleged infringers back to the original complainant. ${ }^{13}$ If after 10-14 days, the complainant has not notified the OSP that it has filed a lawsuit, then the OSP is to reinstate the contested material. 14

12. The requirements for a statutorily-compliant notice are set forth in 17 U.S.C. $\S 512$ (c)(3). A valid $\S 512$ (c)(3)(A) notice must contain (i) identification of the copyrighted work or a representative list of multiple works; (ii) identification of the infringing material; (iii) information that reasonably allows the OSP to locate the infringing material; and (iv) the complainant's contact information. The statute further requires (v) a physical or electronic signature of the complainant; (vi) a statement of good faith that the use of the material is not authorized; and (vii) a statement under penalty of perjury that the notice is accurate; although so long as the statute substantially complies with the first four requirements, the OSP must work with the complainant to bring the notice into full compliance, and then follow the takedown procedure. If there is substantial compliance, the OSP must contact the complainant to help bring the notice into full compliance. 17 U.S.C. $\$ 512(\mathrm{c})(3)(B)(i i)$. A series of cases in California and New York have clarified what it means for a copyright holder to "substantially comply" with the $\S 512(\mathrm{c})(3)$ requirements. The courts have emphasized the importance of including statements of good faith and accuracy and the importance of identifying the allegedly infringing material to the ISP. Hendrickson $v$. eBay found invalid certain DMCA notices which did not contain a statement of good faith and did not identify which copies of a movie were infringing. Although the copyright holder later verbally clarified to eBay that all copies of the movie were infringing, this notification was invalid because it was not written. Hendrickson v. Ebay, Inc., 165 F. Supp. 2d 1082, 1090-91 (C.D. Cal. 2001). In other cases, copyright holders have written in such blanket identifications with no adverse consequences. For example, ALS Scan could properly identify infringing material by stating that virtually all images on two newsgroups violated copyright and by stating each infringing image could be identified by a copyright notification. ALS Scan, Inc. v. RemarQ Comtys., Inc. 239 F.3d 619 (4th Cir. 2001). Indeed, according to $A L S$ Scan, any copyright holder alleging multiple infringements need only provide a representative list of infringing material with one caveat: it is not sufficient to merely list the copyright holders' names without further identification of specific material (i.e. songs) and where it is located. Id. Cybernet in Perfect $10 \mathrm{v}$. Cybernet was found to have a policy that undermined the DMCA notification procedures when it refused to allow representative lists of multiple acts of infringement. Perfect 10, Inc. v. Cybernet Ventures, Inc., 213 F. Supp. 2d 1146, 1179-80 (C.D. Cal. 2002). Cf. Arista Records, Inc. v. MP3Board, Inc., No. 00 CIV. 4660(SHS), 2002 WL 1997918, at $* 8$ (S.D.N.Y. Aug. 29, 2002) (merely listing ten artists in a letter was insufficient, at $* 8-9$, but a letter naming particular artists, specific song titles, and printouts of website screenshots with infringing material did provide adequate notice). Hendrickson $v$. Amazon.com further amplified the "representative lists" provision, holding that a copyright holder cannot rely on a first DMCA notice to validly notify an ISP of subsequent acts of infringement. Hendrickson v. Amazon.com, Inc., 298 F. Supp. 2d 914, 916-17 (C.D. Cal. 2003). A complainant must send a new notice identifying and providing location information for new acts of infringement, because subsequently posted material may be posted at different locations and in different manners.

13. 17 U.S.C. $\S 512(\mathrm{c})$.

14. Presumably, $\S 512(\mathrm{~g})$ provides an incentive for the OSP to reinstate the material. Section 512(g)(1) provides a safe harbor from liability to the OSP's customer for wrongful 
Search engine services are provided safe harbor by $\S 512$ (d). In order to avail themselves of the safe harbor, search engines are also required to "expeditiously" remove complained-of links from their search indexes after receiving notice; however, they are not required to notify the alleged infringer of removal. As search providers likely have no service relationship with the alleged infringer, they rarely have the ability to notify, in any case. Links to complained-of material are thus typically removed from the search engine's index based only on the copyright holder's takedown notice, without any notice to the target or other process. While removing material from a search engine does not remove it from the Internet, it almost certainly will make it more difficult to locate.

The safe harbor provided by the notice-and-takedown procedure is explicitly predicated upon the OSP not having actual or constructive knowledge of infringement before receiving a takedown notice. ${ }^{15}$ Upon receipt of a $\S 512$ (c)(3)(A) notification, regardless of whether the material is actually infringing, and with no independent examination required, an OSP must comply or risk the loss of safe harbor and a lawsuit for contributory copyright infringement. ${ }^{16}$ The OSP's compliance is further encouraged by $\S 512(\mathrm{~g})(1)$, which exempts it from liability for mistaken yet good faith removal of material. The OSP must also expeditiously disclose a user's personal identifying information in accordance with a subpoena issued by the content holder, ${ }^{17}$ as long as the subpoena is accompanied by or

takedown, so long as the $\S 512(\mathrm{~g})(2)$ requirements are met. In turn, $\S 512(\mathrm{~g})(2)$ requires putback within 10-14 days of receipt of a counternotice, so long as the original complainant has not moved the action to court. Although the preservation of this safe harbor appears to be a strong incentive to respond to counternotices, the remedies on behalf of the user are, practically speaking, quite weak. An alleged infringer would have to sue the OSP for wrongful takedown or failure to put back. As OSP service contracts generally specifically limit the OSP's liability for removal or loss of material, the actual incentive to put back seems weak when compared to the incentives to take down. See infra note 26.

15. 17 U.S.C. $\S 512(\mathrm{c})(1)(\mathrm{A})$.

16. "Risk" is the operative word: it is not clear that mere receipt of a notice alleging infringement should rise to the level of "notice of infringement" required for secondary liability. Indeed, some scholars have distinguished between the two, and argued that receipt of a $\$ 512(\mathrm{c})(3)(\mathrm{A})$ notification is not equivalent to "notice" for the purpose of determining secondary copyright liability. See Alfred C. Yen, Internet Service Provider Liability for Subscriber Copyright Infringement, Enterprise Liability, and the First Amendment, 88 GEO. L.J. 1833, 1872-80 (2000); Emily Zarins, Notice Versus Knowledge Under the DMCA's Safe Harbors, 92 CAL. L. REV. 257 (2004).

17. The subpoena process does not apply to $\S 512$ (a) Internet access providers. Recording Industry Association of America v. Verizon Internet Services, Inc., 351 F.3d 1229, (D.C. Cir. 2003), cert. denied, 543 U.S. 924 (2004). 


\section{follows the receipt of a valid (c)(3)(A) notice. ${ }^{18}$ Like 512(a) providers, $\S 512(\mathrm{c})$ providers are required by $\S 512(\mathrm{i})$ to adopt and reasonably implement a policy informing users that accounts of repeat infringers ${ }^{19}$ will be terminated, 20 and to accommodate standard technical measures used by copyright holders to protect their works. ${ }^{21}$}

18. A few courts have considered the proper interpretation of particular requirements for safe harbor and proper $\$ 512(\mathrm{c})(3)$ notification. The cases' main controversies have focused on whether a particular web service fits the statutory definition of an ISP, whether the ISP satisfied the $\$ 512(\mathrm{c})(1)(\mathrm{B})$ and $\S 512$ (i) requirements for safe harbor (see infra note 19), whether the copyright owner sent the ISP a valid $\S 512(\mathrm{c})(3)$ notice (see supra note 12 ), and what remedies are available to innocent individual whose material has been removed (see infra note 30). Some parameters on safe harbor set by courts thus far include a decision that safe harbor does not extend to violations of the anti-circumvention provisions of the DMCA and that $\$ 512(\mathrm{c})(3)$ notifications (as well as $\S 512(\mathrm{~h})$ subpoenas) cannot be validly served on $\S 512$ (a) "mere conduit" service providers. See Universal City Studios, Inc. v. Reimerdes, 82 F. Supp. 2d 211 (S.D.N.Y. 2000); RIAA, Inc. v. Verizon Intemet Services, Inc., 351 F.3d 1229 (D.C. Cir. 2003).

19. Copyright plaintiffs have attempted to prove the OSP is ineligible for safe harbor due to non-compliance with the $\S 512(\mathrm{i})(1)(\mathrm{A})$ requirement that the OSP adopt and reasonably implement a policy to terminate service to repeat infringers. Courts have generally agreed that OSPs must establish and reasonably implement such a policy in order to qualify for safe harbors, but have not yet established firm guidelines as to what constitutes reasonable implementation. In Ellison v. Robertson, the Ninth Circuit agreed that OSPs must indeed "reasonably implement" a repeat infringer policy. Ellison v. Robertson, 357 F.3d 1072, 1080 (9th Cir. 2004) (allowing notifications to be sent to an invalid e-mail address raised questions of fact as to reasonable implementation). Courts have examined the question, but few courts have withheld safe harbor from ISPs based on failure to "reasonably implement" a policy of terminating multiple infringers. See Corbis v. Amazon.com, 351 F. Supp. 2d 1090 (W.D. Wash. 2004) (prior termination can demonstrate implementation and imperfect implementation does not disqualify for the safe harbor); Perfect 10 v. CCBill, 340 F. Supp. 2d 1077, 1088 (C.D. Cal. 2004) (failure to terminate client accounts after repeat notices is not reasonable implementation). Plaintiffs have had more success with this argument in the realm of peer-to-peer software applications. See In re Aimster Copyright Litig., 252 F. Supp. 2d 634 (N.D. Ill. 2002) (finding that Aimster had "eviscerated" its ability to reasonably implement a policy by encrypting user communications), aff $d$, 334 F.3d 643, 655 (7th Cir. 2003). A\&M Records, Inc. v. Napster, Inc., 239 F.3d 1004 (9th Cir. 2001) (affirming injunction based on finding in another motion that Napster may have failed to adopt a policy in a timely fashion or to reasonably implement it) (affirming A\&M Records, Inc. v. Napster, Inc., 114 F. Supp. 2d 896, and citing A\&M Records, Inc. v. Napster, Inc., No. C 99-05183 MHP, 2000 WL 573136 (N.D. Cal. May 12, 2000)). It remains to be seen whether the holdings in the P2P context will be harmonized with the holdings in other OSP contexts.

20. A number of plaintiffs have argued that an OSP's power to remove or disable access to material or terminate user accounts disqualifies the OSP from safe harbor under $\S 512(\mathrm{c})(1)(\mathrm{B})$; that the power to remove content is effectively an editorial function. Four cases rejected this blanket rule, which would undermine $\S 512$ (i) and the general intent of $\S 512$. Instead, the courts stated an OSP must do more than merely have the power to remove content to demonstrate an ability to control infringement; for example, advise individual webmasters on content. Perfect 10, Inc. v. Cybernet Ventures, Inc. 213 F. Supp. 2d 1146, 1181-82 (C.D. Cal. 2002); Ellison v. Robertson, 189 F. Supp. 2d 1051, 1061 (C.D. Cal. 2002), rev'd in part, Ellison v. Robertson. 357 F.3d 1072 (9th Cir. 2004); Hendrickson v. eBay, Inc., 165 F. Supp. 2d 1082, 1093 (C.D. Cal. 2001); Costar Group Inc. v. Loopnet, Inc., 164 F. Supp. 2d 688, 704 (D. Md. 2001). In particular, one court emphasized that OSPs do not lose safe harbor by adopting 
Protections for the target of the notice (the alleged infringer) are relatively few, as material can come down in advance of notice to the target, and judicial protection is not available unless three things occur: the target elects to submit a counternotice; the complainant then files suit; and a court reviews the issue. ${ }^{22}$ One important protection for subscribers is receiving notice of the copyright holder's complaint, which is afforded only to Internet subscribers of hosting services under $\S 512(\mathrm{c})$, and not to beneficiaries or subscribers of other regulated services, such as $\S 512$ (d) search services or $\S 512$ (a) Internet access providers. Section 512(g) requires that the service provider notify the user in order to maintain a liability exemption for mistaken removal.23 This triggers the second important procedural protection. Alleged infringers, upon notice of takedown, can send a valid $\S 512(\mathrm{~g})(3)$ counter-notification to the service provider containing (A) a physical or electronic signature; (B) identification of the material removed and its former location; (C) statement under penalty of perjury that the user has a good faith belief the material was mistakenly removed; (D) the user's name, address, and phone number; and (E) consent to the jurisdiction of Federal District Court. If it receives a valid counternotice, the OSP must then advise the copyright complainant that it will put back the material in 10-14 days unless it receives notice from the complainant that the complainant has filed a court action. ${ }^{24}$ Unless a copyright owner chooses not to seek judicial remedy following receipt of the counter-notification, a takedown target must be prepared to defend the challenged use in a Federal District Court. Assuming a lawsuit is not filed, then the target must hope that the OSP will reinstate the material.

voluntary programs to reduce infringement. Hendrickson v. eBay, Inc. 165 F. Supp. 2d 1082, 1094 (C.D. Cal. 2001). Perfect10 v. CCBilllikewise held that screening for red flag infringements, blatantly illegal conduct, does not close off the safe harbor. $340 \mathrm{~F}$. Supp. 2d 1077 (C.D. Cal. 2004).

21. What "accommodation" means has yet to be determined.

22. In cases of a knowing, material misrepresentations that the material is infringing, the alleged infringer also may sue under $\S 512(\mathrm{f})$. See infra note 28 and accompanying text.

23. An OSP is not required to notify its consumer that it has removed material. However, $\S 512(\mathrm{~g})$ provides an incentive for hosting service OSPs to do so, by providing a safe harbor against claims by the user for the OSPs good faith removal of content, if the OSP "takes reasonable steps promptly to notify the subscriber that it has removed or disabled access to the material." $\$ 512(\mathrm{~g})(2)(\mathrm{A})$. A consumer's claims against an OSP are likely limited by the terms of service, in any case. Thus, e-mail notification to the wrong e-mail address may well suffice, as might notification to users on vacation, users with temporarily malfunctioning e-mail accounts, or users with any of a host of other e-mail access problems.

24. 17 U.S.C. $\S 512(\mathrm{~g})(2)(\mathrm{B})-(\mathrm{C})$. 
The statute provides encouragement to OSPs to replace wrongfully or mistakenly targeted material. Section $512(\mathrm{~g})(1)$ offers OSPs a safe harbor from liability to their subscribers for wrongful takedown, but conditions that safe harbor on $\S 512(\mathrm{~g})(2)$, which requires OSPs to notify targets that they will put back material if a counternotice is received, unless the OSP receives notice that a legal action was filed. Specifically, the OSP must first notify the complainant that it "will" reinstate the content within ten business days after receipt of a counternotice; and then the OSP must "replace[] ... and cease[] disabling access" to the material within fourteen days after receipt of a counternotice. ${ }^{25}$ However, while in theory an OSP might be subject to some tort or contractual liability for a wrongful takedown of content, in practice, OSPs limit their liability with their terms of service. ${ }^{26}$ Hence, although the statute seeks to encourage putback by providing a safe harbor against liability for wrongful takedown, in actuality, OSP service contracts limit most legal or financial incentives for OSPs to do so.

Remedies for bad faith action are provided by $\S 512(\mathrm{f})$. Under $\S 512(\mathrm{f})$, any of the three parties - the copyright holder, the alleged infringer, or the OSP - can be awarded damages, costs and attorneys' fees if either the copyright holder or alleged infringer makes knowing, material misrepresentations in a notice or counternotice. Section 512(f) sets a high bar to recovery: copyright holders may send insufficient or vague notices, and even send notices on suspicion instead of diligent investigation, without triggering $\S 512(\mathrm{f}) .27$ While high, however, the "material misrepresentations" bar is not unreachable. In Online Policy Group v. Diebold, a District Court judge found that the copyright holders were subject to $\S 512(\mathrm{f})$ for sending notices because they should have known that reproduction and distribution of the company's private internal memos, discussing voting technology flaws, were a fair use. ${ }^{28}$ Though the court in Diebold certainly gave some teeth to $\S 512(\mathrm{f})$, cases that relate to materials so widely publicized and so central to democracy are likely

25. Id.

26. See, e.g., AOL Terms of Service, http://about.aol.com/aolnetwork/aolcom_terms; Blogger Terms of Service, http:/www.blogger.com/terms.g; Yahoo! Geocities Terms of Service, http://docs.yahoo.com/info/terms/geoterms.html, Clause 11 ("Yahoo reserves the right at any time and from time to time to modify or discontinue, temporarily or permanently, the Service (or any part thereof) with or without notice. You agree that Yahoo shall not be liable to you or to any third party for any modification, suspension or discontinuance of the Service.").

27. Arista Records, Inc. v. MP3Board, Inc., No. 00 CIV. 4660(SHS), 2002 WL 1997918, at *15 (S.D.N.Y. Aug. 29, 2002).

28. Online Policy Group v. Diebold, Inc., 337 F. Supp. $2 d 1195$ (N.D. Cal. 2004). 
rare, ${ }^{29}$ and no other $\S 512(\mathrm{f})$ cases have dealt such a blow to the complainant. ${ }^{30}$ Moreover, for a complainant to "know" with legal certainty that its complaint targets a non-infringing or fair use is often unrealistic, given the complexity of copyright infringement analysis and the famed unpredictability of the fair use defense. ${ }^{31}$

In addition to largely unsuccessful reliance on $\S 512(f),{ }^{32}$ accused infringers have also initiated lawsuits against the complaining copyright holder for intentional interference with contractual relations, intentional interference with prospective business

29. The Diebold court noted that "[i]t is hard to imagine a subject the discussion of which could be more in the public interest." Online Policy Group v. Diebold, 337 F. Supp. 2d 1195, 1203 (N.D. Cal. 2004).

30. The Rossi court noted that the cause of action under $\S 512(f)$ is limited to situations where the misrepresentation is "knowing,", and that a subjective belief that materials were infringing, even if the belief was incorrect, did not qualify as a "knowing" misrepresentation. Rossi v. Motion Picture Ass'n of America, 391 F.3d 1000, 1004-05 (9th Cir. 2004). The Dudnikov court determined that the complainant had not committed a violation of $\S 512(\mathrm{f})$ because MGM had not made "knowing and material misrepresentations" or acted in bad faith in sending the notice. Dudnikov v. MGM Entertainment, Inc., Civil Action No. 03-D-2512 (PAC), 2005 U.S. Dist. LEXIS 38511 (D. Colo. Aug. 17, 2005). The MP3Board court found that inadequate notice does not constitute a "material misrepresentation" for the purposes of \$ 512(f)). Arista Records, Inc. v. MP3Board, Inc., No. 00 CIV. 4660(SHS), 2002 U.S. Dist. LEXIS 16165, at 43-46 (S.D.N.Y. Aug. 29, 2002).The ALS Scan court hinted, in dicta, at a broader reading of $\S 512(\mathrm{f}):$ "To the extent that ALS Scan's claims about infringing materials prove to be false, RemarQ has remedies for any injury it suffers as a result of removing or disabling noninfringing material." ALS Scan, Inc. v. RemarQ Communities, Inc., 239 F.3d 619, 625 (4th Cir. 2001). The Corbis court only briefly discussed "knowing misrepresentation," analogizing the $\S 512(\mathrm{f})$ standard to the standard of knowledge that an ISP must possess before potentially liable for secondary copyright liability. Corbis v. Amazon.com, 351 F. Supp. 2d 1090, $1105-06$ (W.D. Wash. 2004).

31. David Nimmer, The Public Domain: 'Fairest of Them All' and Other Fairy Tales of Fair Use, 66 LAW \& CONTEMP. PROB. 263 (2003) (attempting to objectively assess fair use cases decided since the 1976 Copyright Act and finding them entirely unpredictable) ("Basically, had Congress legislated a dartboard rather than the particular four fair use factors embodied in the Copyright Act, it appears that the upshot would be the same. . . Courts must therefore proceed by the seat of their pants." Id. at 280, 281.). See also Pierre N. Leval, Toward a Fair Use Standard, 103 HARV. L. REV. 1105 (1990):

Judges do not share a consensus on the meaning of fair use. Earlier decisions provide little basis for predicting later ones. Reversals and divided courts are commonplace. The opinions reflect widely differing notions of the meaning of fair use. Decisions are not governed by consistent principles, but seem rather to result from intuitive reactions to individual fact patterns. Justification is sought in notions of fairness, often more responsive to the concerns of private property than to the objectives of copyright.

Id. at 1106-07.

32. See id. 
advantage, and even intentional infliction of emotional distress. ${ }^{33}$ Thus far, none of these claims have succeeded. ${ }^{34}$

Section 512 obviously operates in a complex manner; courts will, of course, continue to develop caselaw around its requirements and limitations. As we see in Section V, however, the vast majority of $\S 512$ notices likely are never subject to the scrutiny of a court. In part, this was precisely the point behind $\S 512$ : the efficient removal of infringing materials from the Internet in a fair process, with (in most cases) no need for court review. In the next section, we briefly sketch the rationale behind $\S 512$ and some concerns that accompanied its passage.

\section{THE RATIONALE BEHIND $§ 512$ AND HISTORICAL CONCERNS}

Section 512 grew from Congressional attempts to respond to two major constituents: the content industry and online service providers. ${ }^{35}$ In 1997, online service providers-ISPs, search engines, and others-began lobbying Congress for a safe harbor from secondary liability based on their customers' copyright infringement. ${ }^{36}$ OSPs arguably faced a high degree of uncertainty about contributory and vicarious liability due to conflicting interpretations of when they could be held secondarily liable for their customers' infringement. ${ }^{37}$ District Courts in Religious Technology Center v. Netcom ${ }^{38}$ and Marobie-FL Inc. v. National Assoc. of Fire Equip Distributors ${ }^{39}$ had shielded OSPs from liability for users' acts

33. Arista Records, 2002 WL 1997918; MP3Board v. Recording Industry Ass'n of Am., Inc., No. C-00-20606 RMW, 2001 WL 804502 (N.D. Cal. Feb. 27, 2001) (staying claims until New York decision; the New York decision denied the California tort claims); Rossi v. Motion Picutre Ass'n of Am., Inc., 2003 WL 21511750, 2003 U.S. Dist. LEXIS 12864, No. 0200239BMK (D. Haw. Apr. 29, 2003), aff'd, Rossi v. Motion Picture Ass'n of Am., Inc., 391 F.3d 1000 (9th Cir. 2004); Dudnikov v. MGA, No. 03-D-2512 (PAC), 2005 U.S. Dist. LEXIS 38511 (D. Colo. Aug. 17, 2005).

34. Rossi, 2003 U.S. Dist. LEXIS 12864 , at *7-8, *14.

35. See, e.g., Statement of Senator Hatch, 105th Congress, 144 CONG. REC. S4884-01 (May 14, 1998) ("Title II, for example, reflects 3 months of negotiations between the major copyright owners and the major OSPs, and ISPs....").

36. See Cassandra Imfeld \& Victoria Smith Ekstrand, The Music Industry and the Legislative Development of the Digital Millennium Copyright Act's Online Service Provider Provision, 10 COMM. LAW \& POLICY 29 (2005).

37. See Mitchell P. Goldstein. Service Provider Liability for Acts Committed By Users: What You Don't Know Can Hurt You. 18 J. MarShall J. COMPUTER \& INFo. L. 591, 613 (2000).

38. Religious Technology Center v. Netcom, 907 F. Supp. 1361 (N.D. Cal. 1995).

39. Marobie-FL Inc. v. National Assoc. of Fire Equip. Distribs., 983 F. Supp. 1167 (N.D. IIl. 1997). 
of copyright infringement. At the same time, Playboy Enterprises, Inc. v. Frena ${ }^{40}$ and Sega Enterprises Ltd. v. MAPHIA ${ }^{41}$ found bulletin board operators liable for direct copyright infringement despite the fact that it was users who-independent of knowledge or control by the OSP-had uploaded or downloaded the infringing material.42 OSPs raised concerns about this mix of decisions, and sought greater certainty from Congress, which took up the concerns and addressed them with $\S 512.43$

Representatives from major copyright holders, on the other hand, wanted OSPs to police their networks and opposed any safe harbor that did not require OSPs to do so. They pointed out that, in 1995, the Clinton Administration's Information Infrastructure Task Force's Working Group on Intellectual Property Rights had opined that no legitimate justification existed for giving OSPs special exemption

40. Playboy Enterprises, Inc. v. Frena, 839 F. Supp. 1552 (M.D. Fl. 1993).

41. Sega Enterprises Ltd. v. MAPHIA, No. CIV. A. 93-4262 CW, 1997 WL 337558, (N.D. Cal. June 9, 1997).

42. The expansive reading of vicarious liability in Fonovisa v. Cherry Auction inspired worries that financial revenues derived from providing access to the Internet could result in vicarious liability, as well. Fonovisa v. Cherry Auction, Inc., 76 F.3d 259 (9th Cir. 1996). OSPs were concerned that applications of the Fonovisa standard in the Internet context could result in a finding that OSP's access fees might constitute "direct financial benefit". Id. See also Michelle A. Ravn, Navigating Terra Incognita: Why the Digital Millennium Copyright Act Was Needed to Chart the Course of Online Service Provider Liability for Copyright Infringement, 60 OHIO ST. L.J. 755, 785 (1999); I. TROTTER HARDY, U.S. COPYRIGHT OfFICE, PROJECT LOOKING FORWARD: SKETCHING THE FUTURE OF COPYRIGHT IN A NETWORKED WORLD 133 (May 1998), available at http://www.copyright.gov/reports/thardy.pdf. Section 512 guaranteed that the direct financial benefit prong would not be satisfied by an OSP's collection of general fees but only by receipt of extra revenue directly generated by access to infringing materials. S. REP. 105-190, at 45. Under $\S \S 512(\mathrm{c})(1)(\mathrm{B})$ and (d)(1)(B), OSPs are not liable if, among other things, the OSP "does not receive a financial benefit directly attributable to the infringing activity, in a case in which the service provider has the right and ability to control such activity" (emphasis added). This restates the vicarious liability standard with a gloss that would apparently exclude Fonovisa's broader recognition of "substantial financial benefits from admission fees, concession stand sales and parking fees". Fonovisa, 76 F.3d 259, 263. OSPs may still face vicarious liability, but only if the financial benefit is "directly attributable" to the infringing activity.

43. See, e.g., H.R. REP. 105-551(I), May 22, 1998, encompassing the submitted favorable report from the Committee for the Judiciary:

The "On-Line Copyright Infringement Liability Limitation Act" addresses concerns raised by a number of on-line service and Internet access providers regarding their potential liability when infringing material is transmitted on-line through their services. While several judicially created doctrines currently address the question of when liability is appropriate, providers have sought greater certainty through legislation as to how these doctrines will apply in the digital environment. 
from the copyright liability schema. ${ }^{44}$ The Working Group considered that OSPs should be no more exempt from policing information for copyright infringement than photo labs, booksellers and newsstands, which also face the challenges of policing large amounts of material. 45 Instead, the Working Group recommended reliance on developing caselaw and judicial contemplation of an OSP's duty to copyright holders in the face of knowledge of, or direct financial benefit from, copyright infringement. According to the Working Group, the business relationship between OSPs and Internet users justified placing the risk and cost of liability on OSPs. ${ }^{46}$ Under this view, placing the burden on OSPs was an efficient choice, as OSPs could reduce risk with user indemnification agreements and appropriate insurance. ${ }^{47}$ And the threat of monetary liability facing OSPs was necessary to achieve settlements between OSPs and copyright owners and to create adequate incentives for OSPs to control piracy. ${ }^{48}$ Likeminded scholars felt that OSPs were best situated to prevent infringement ${ }^{49}$ and that moderate court decisions focusing on vicarious and contributory liability would produce solutions that would increasingly converge on a fair and "workable" standard. ${ }^{50}$

Amidst these negotiations between the industries and Congress, consumers of both industries, as well as representatives from educational institutions and libraries, raised due process and First Amendment concerns and lobbied for particular concessions. ${ }^{51}$ Universities protested that they might too easily be disqualified from

44. BRUCE A. LEHMAN, INTELlECTUAL PROPERTY AND THE NATIONAL INFORMATION INFRASTRUCTURE: THE REPORT OF THE WORKING GROUP ON INTELLECTUAL PROPERTY RIGHTS 114-24 (Sept. 1995), available at http:/www.uspto.gov/web/offices/com/doc/ipnii/.

45. Id. at 117 .

46. Id.

47. Id. at 117-18, 123 .

48. See Daniel R. Cahoy. Comment: New Legislation Regarding On-Line Service Provider Liability for Copyright Infringement: A Solution in Search of a Problem? 38 IDEA 335,359 (1998).

49. See Jane C. Ginsburg, Putting Cars on the 'Information Superhighway': Authors, Exploiters, and Copyright in Cyberspace, 90 COLUM. L. REV. 1466, 1492-93 (1995).

50. See Cahoy, supra note 48 , at 353.

51. See, e.g., 144 CONG. REC. S4435-04, S4438 (Statement of Senator Leahy). The Digital Future Coalition (DFC) organized much of the consumer-oriented response, including heritage organizations, libraries, consumer organizations, and various technology groups. Among the technology groups were the Home Recording Rights Coalition (HRRC), which has continued to be active on behalf of consumers and the consumer technology industry. Both the DFC and HRRC websites include overviews of relevant DMCA legislative history. See DFC, DMCA Timeline, http://dfc.org/dfc1/Active_Issues/graphic/graphic.html; and HRRC, DMCA Timeline, http://hrrc.org/dmca/dmca history.html. 
limited liability because their role as OSPs is complicated by employer-employee (respondeat superior) relationships with faculty users. ${ }^{52}$ An amendment from Senator Feinstein protected educational institutions from being held liable for some faculty and graduate student employees' acts of infringement. 53 Both universities and libraries had also protested that the proposed extra-judicial procedures for removing users' material from the Internet violated constitutional provisions for due process. ${ }^{54}$ In response, the Senate Committee on the Judiciary accepted the Ashcroft-Leahy-Hatch amendment, which added procedural protections in the form of the $\S 512(\mathrm{~g})^{55}$ counternotice process for Internet users to challenge the removal of material from the Internet. It did not, however, address deeper due process concerns. Committee members thought, among other reasons, that Internet service contracts limited any state property law basis for users' due process claims, and that the procedural protections were sufficient. 56

With these amendments, the Senate Committee on the Judiciary unanimously decided on April 30, 1998, to favorably report the

\section{S. REP. NO. 105-190, at 20 (1998).}

53. 144 CONG. REC. S4889. The Feinstein amendment is codified at 17 USCA $\$ 512(\mathrm{e})$. The educational institution would only be liable if under subsection (A) the infringement involved online access to instructional materials for a course taught within the previous 3 years; if under subsection (b) the institution received more than two valid notifications of infringement; or if under subsection (c) the institution failed to inform its users of and promote compliance with U.S. copyright law.

54.

The second concern raised about the applicability of section 512 to public universities and libraries, and indeed other public entities which operate as online service providers, is that by complying with the notice-and-takedown provisions of section 512, the public entities might violate the due process rights of their users.

S. REP. No. 105-190, at 20 (1998).

55. 17 USCA $\S 512(\mathrm{~g})$.

56.

Any such due process objection suffers at least two flaws. In the first place, a prerequisite to any due process claim is a state law property interest. In the case of the relatively new concept of Internet access, the service provider contract, rather than any common law property interest, would appear to be the yardstick of the Internet user's property interest in continued access. The contract for Internet service, therefore, can limit any property interest that would form the basis for a procedural due process claim. Second, and even more important, the procedural protections afforded by the notification requirements of subsection 512 (c)(3) and the provisions for the replacement of removed or disabled materials in subsection 512 (f) provide all the process that is due.

S. REP. NO. 105-190, at 20 (1998). 
legislation. 57 The House Subcommittee on Telecommunications, Trade, and Consumer Protection did likewise on July 18, 1998, when it also unanimously decided to favorably report the legislation to the House, including educational and counter-notification amendments similar to those added in the Senate. ${ }^{58}$ The legislation continued to receive widespread support. ${ }^{59}$ Five months later, on October 8, 1998, the Senate unanimously passed the Conference Report on the DMCA. ${ }^{60}$ The House-Senate conference unanimously supported the final version of the legislation, ${ }^{61}$ and the House passed the legislation by voice vote on October 12, 1998.62 President Clinton was able to announce upon his signing of the bill on October 28, 1998, that, "[t]hrough enactment of the Digital Millennium Copyright Act, we have done our best to protect from digital piracy the copyright industries that comprise the leading export of the United States." 63

While debates surrounding the legislation included the limited discussion noted above, no extended discussion arose concerning the implications the extra-judicial removal procedure might have on freedom of expression on the Internet or due process for alleged infringers. Senator Ashcroft, however, did address his initial concerns and the purpose behind the counternotice and putback provisions in remarks on the Senate floor:

Although I was supportive of the affected industries' efforts to resolve the OSP liability issues, there was one issue which the industry agreement did not address - what protections would be given the typical users of the Internet. The agreement protected the interests of OSPs, and it protected the interests of copyright owners, but it provided little or no protection for an Internet user wrongfully accused of violating the copyright laws.

The original draft would have left these wrongly injured, innocent users with limited recourse. They would have to hire an attorney and go to court to have the court require the OSP and copyright holder to allow the web page to go back up-in other words the end user would have to go to court to prove their innocence. I found this situation to be totally unacceptable. Even though several

57. S. REP. No. 105-190, at 7 (1998).

58. H.R. REP. 105-551(II), available at 1998 WL 414916, at 28.

59. See 144 CONG. REC. S12730-01.

60. H.R. 2281. 144 CONG. REC. S12375-02, S12375.

61. 144 CONG. REC. S11887-01, S1 187.

62. 144 CONG. REC. S12375-02, S12375.

63. Digital Millennium Copyright Act, P.L. 105-304, 1998 U.S.C.C.A.N. 671, 1998 WL 971790 (Statement by President William J. Clinton upon Signing H.R. 228). 
Judiciary Committee members claimed that no amendments were needed I made sure that the industry compromise protected the rights of the typical Internet user by offering an amendment that provided protection included [in] my original bill-an idea referred to as notice and put back. If material is wrongly taken down from an Internet user's home page because the original notice mistakenly did not take into account that the Internet user was only making a fair use of the copyrighted work, my amendment ensures that the end-user will be given notice of the action taken, and gives them a right to initiate a process that allows them to put their material back on-line, without the need to hire a lawyer and go to court. This was a critical improvement over the industry's compromise agreement. 64

Whether the procedural protections provided by $\S 512$ are sufficient to address concerns, however, has thus far been unclear. Additionally, whether the planned benefits of $\S 512$ have come to fruition is a question that has been unanswered. In theory, granting OSPs safe harbor from contributory copyright infringement for their removal of material in response to a DMCA notice has several benefits. First, it greatly diminishes any incentive for OSPs to monitor their users' Internet expression for fear of secondary liability. Second, it is, at least theoretically, less burdensome on OSPs than any scheme that would require them to monitor their users' behavior. Third, it is a quick and easy way for victims of copyright infringement to shortcircuit Internet distribution of copyrighted material-probably faster, and certainly much less expensive, than obtaining a temporary restraining order or preliminary injunction from a court. The alleged infringer is in the position of having material removed before any court review; but the counternotice procedure is also quick and easy.

While $\S 512$ provides victims of copyright infringement a quick, simple way to police their copyrights on the Internet, concerns arise from two directions. First, implementing $\S 512$ is at least a moderate burden on OSPs, who have to establish procedures and absorb the cost of enforcement. For small providers especially, this may be a greater burden than anticipated during debate over $\S 512$. Second, alleged infringers are subject to removal of their expressive materials, not only before a judge reviews the complaint, but likely even before they receive notice of a complaint. Further, while they have the

64. 144 CONG. REC. S4884-01, 4889 (May 14, 1998) (Statement of Sen. Ashcroft). 
opportunity to send a counternotice, the material, once removed, 65 must stay down at least 10-14 days according to the statute. The effect may be to substantially burden expressive and other individual rights. In the case of expressive materials, this could be especially significant: ten days to two weeks may greatly diminish the value of the call to a protest, the competitive price, or the newsworthy blog entry.

These competing visions of $\S 512$ have persisted since it took effect. Some legal commentators heralded $\S 512$ 's enactment as the economic salvation of the Internet. ${ }^{66}$ Undeniably, $\S 512$ demonstrates that Congress recognized both OSPs' concerns about a crisis facing them in the courts, and the rationality of limiting their liability. ${ }^{67}$ Not all observers applauded, however. A few commentators argued that $\S 512$ struck the wrong balance and failed copyright holders by removing incentives-by, in fact, providing disincentives-for OSPs to monitor their networks and prevent copyright infringement, despite the fact that they were in the best position to do so. ${ }^{68}$ Another camp of critics doubted the rosy picture of user rights. These commentators were supportive of a rule that discouraged OSPs from monitoring

65. The statute is silent as to the situation where a user does receive notice, and sends a counternotice back to the OSP before the material is removed. In an era of rapid communications, it is possible that this situation could arise.

66. See Jennifer L. Kostyuu, Comment, Copyright Infringement on the Internet: Determining the Liability of Internet Service Providers, 48 CATH. U.L. REV. 1237, 1270 (1999); Michelle A. Ravn. Navigating Terra Incognita: Why the Digital Millennium Copyright Act Was Needed to Chart the Course of Online Service Provider Liability for Copyright Infringement, 60 OHIO ST. L.J. 755, 785-86 (1999); Conference: Franklin Pierce Law Center's Seventh Biennial Intellectual Property System Major Problems Conference Digital Technology and Copyright: $A$ Threat or a Promise?, 39 IDEA 291, (Comments of Mr. Frank Politano, Mr. Matt Oppenheim) (1999); Steven E. Halpern. New Protections for Internet Service Providers: An Analysis of "The Online Copyright Infringement Liability Limitation Act, 23 SETON HALL LEGIS. J. 359, 406-07 (1999).

67. A number of courts, and commentators, have compared the $\$ 512$ safe harbor with 47 U.S.C. $\$ 230$, expressing dismay that tortious speech on the Internet receives less sanction than copyright infringement. See, e.g., Batzel v. Smith, 333 F.3d 1018 (9th Cir. 2003); Barret v. Rosenthal, 9 Cal. Rptr. 3d 142 (previously published at 114 Cal. App. 4th 1379) (Cal. Ct. App. 2004) (certified for partial publication). See also Michael L. Rustad \& Thomas H. Koenig, Rebooting Cybertort Law, 80 WASH. L. REV. 335 (2005); Sarah Duran, Note, Hear No Evil, See No Evil, Spread No Evil: Creating a Unified Legislative Approach to Internet Service Provider Immunity, 12 U. BALT. INTELL. PROP. L.J. 115 (2004); Jonathan Band \& Matthew Schruers, Safe Harbors Against the Liability Hurricane: The Communications Decency Act and the Digital Millennium Copyright Act, 20 CARDOzO ARTS \& ENT. L.J. 295 (2002).

68. See, e.g., Colin Folawn, Neighborhood Watch: The Negation of Rights Caused by the Notice Requirement in Copyright Enforcement Under the DMCA, 26 SEATTLE U. L. REV. 979 (2003). 
their users, but worried that the takedown procedures abrogated due process and could chill Internet expression. 69

Under the latter critics' view, $\S 512$ gives OSPs strong incentives to maintain their safe harbor and few incentives to question takedown, even in instances where a secondary liability suit would likely fail and even in instances where allegations of copyright infringement are dubious. ${ }^{70}$ Under this paradigm, users are inadequately protected by $\S 512$ 's provision that invalid notices would not give rise to OSP liability under the awareness standard. The OSP bears the risk of liability if it decides to ignore a notice as invalid if, after the fact, a court deems the notice to substantially comply with the statute's provisions. Similarly, the OSP would lose the safe harbor if it decided not to comply with a particular notice in the belief that a copyright holder knowingly misrepresented the allegation of infringement when the copyright holder had simply made a mistake or otherwise did not have the requisite intent to misrepresent. Since the OSP is largely immunized from acting on a notice in good faith ${ }^{71}$ but not from failing to act on a notice in good faith, the OSP is likely to always err on the side of caution and on the side of the complaining copyright holder. ${ }^{72}$ The statute also requires the OSP to assist the copyright holder in issuing a technically valid notice, further diminishing incentives to ignore faulty notices. Given the overall incentive structure set out by the statute, it is likely in the OSP's interest, in

69. See Alfred C. Yen, Internet Service Provider Liability for Subscriber Copyright Infringement, Enterprise Liability, and the First Amendment, 88 GEO. L.J. 1833, 1888 (2000); Emily Zarins, Notice Versus Knowledge Under the DMCA's Safe Harbors, 92 CAL. L. REV. 257, 291-95 (2004).

70. See Conference: Franklin Pierce Law Center's Seventh Biennial Intellectual Property System Major Problems Conference, Digital Technology and Copyright: A Threat or a Promise? 39 IDEA 291, 301-03 (Statement of Mr. Jeremy Williams); Mark D. Robins, Counter Notification Under the Digital Millennium Copyright Act: A Gap in the Safe Harbor, CyberspaCe Lawyer, Nov. 1999, at 5; Malla Pollack, The Right to Know? Delimiting Database Protection at the Juncture of the Commerce Clause, the Intellectual Property Clause and the First Amendment, 17 CARDOZO ARTS \& ENT. L.J. 47, 109 (1999); Alfred C. Yen, Internet Service Provider Liability For Subscriber Copyright Infringement, Enterprise Liability, and the First Amendment, 88 GEO. L.J. 1833, 1883 (2000).

71. See supra note 14 and accompanying text for further discussion about the practical limitations of OSP liability for takedown.

72. See Conference: Franklin Pierce Law Center's Seventh Biennial Intellectual Property System Major Problems Conference Digital Technology and Copyright: A Threat or a Promise? 39 IDEA 291, 372 (Statement of Mr. Bill Murphy predicting OSPs will comply even with dubious notices such as those sent by the Church of Scientology to silence critics). 
terms of time and efficiency, to act on the faulty notice rather than pursue a valid one. ${ }^{73}$

Procedurally, §512 substitutes the OSP's self-interested mediation of copyright infringement for official and neutral judicial mediation. Internet users enter the process to defend their use of material only after the private process has resulted in the equivalent of a temporary restraining order being issued against the user. As putback is, practically, not guaranteed, ${ }^{74}$ the $\S 512(\mathrm{c})$ and (d) noticeand-takedown process, therefore, effectively constitutes an extrajudicial temporary restraining order, based solely on the copyright holder's allegation of copyright infringement. Even after the alleged infringer issues a challenge to the allegations, this TRO-like situation remains in effect as long as the copyright owner is willing to sue within the 10-14 days and regardless of the likelihood of success on the merits. ${ }^{75}$ In addition, the remedies available to alleged infringers whose expression is improperly subject to a takedown are generally limited to situations where there was "knowing material misrepresentation" by the entity filing the DMCA notice. Legally speaking, this is a difficult standard to meet.

Supporters were also dismissive of these user-oriented concerns, arguing that, far from chilling speech, $\S 512$ actually would promote the democratic quality of the Internet. Under this view, the fact that $\S 512$ confers no duty on OSPs to police their users protects users from a significant chilling of constitutionally protected expression. ${ }^{76}$ Indeed, following $\S 512$ 's adoption, strategists advised businesses to reduce all monitoring of their hosting and linking services and all control of users' activities in order to avoid triggering the "facts and circumstances" knowledge standard in $\S 512$ (c)(1)(a)(ii) and $\S 512(\mathrm{~d})(1)(\mathrm{A})(\mathrm{B}){ }^{77}$ Furthermore, the Associate Register for Policy

73. See Alfred C. Yen, Internet Service Provider Liability For Subscriber Copyright Infringement, Enterprise Liability, and the First Amendment, 88 GEO. L.J. 1833, 1884 (2000); Thorny Legal Issues: Web Site Provider Liability For User Content and Actions, MULTIMEDIA \& WeB Strategist. Vol 5, No, 4. Jan. 1999.

74. See supra note 14 and accompanying text for further discussion about the practical limitations of OSP liability for takedown.

75. In addition, we have found little evidence of either counternotice use or putback. See infra Section V.G. While this is a continuing research question for us, if putback is not occurring in appropriate circumstances, the process becomes more akin to an extra-judicial injunction than a TRO-a dramatic realignment of traditional legal procedures that protect defendants.

76. Steven E. Halpern. New Protections for Internet Service Providers: An Analysis of The Online Copyright Infringement Liability Limitation Act, 23 SETON HALL LEGIS. J. 359, $407-$ 08 (1999).

77. Thorny Legal Issues: Web Site Provider Liability for User Content and Actions. Multimedia \& Web Strategist. Vol. 5, No. 4. Jan. 1999. 
and International Affairs of the United States Copyright Office thought that $\S 512$ offered legitimate users more substantive protection than the informal system of notice and takedown that OSPs and copyright holders were then practicing. ${ }^{78}$ Under the pre- $\S 512$ regime of informal arrangements, users had to establish elements of a common law claim against an OSP who improperly removed material; Section 512's process handed users a new statutory cause of action directly against the content owner whereby the user could be reimbursed for costs incurred for wrongful takedowns. ${ }^{79}$

Overall, those who are concerned about $\S 512$ 's possible effects point out that the question of secondary liability for OSPs is unsettled anyway, and that the medicine may prove worse than the disease of uncertainty. ${ }^{80}$ Moreover, the more OSPs rely upon the DMCA safe harbor, the less opportunity courts will have to clarify existing caselaw on OSP liability, and the more DMCA compliance, with its attendant bias toward takedown (see, e.g, infra), will be "a permanent feature of the legal landscape" for OSPs. ${ }^{81}$ In addition, while there is some conflicting caselaw on $\S 512(c)$ (hosted material) situations, providing mere hypertext links through a search engine seems unlikely under current law to result in secondary liability for search OSPs in the first place, regardless of $\S 512(d)$ 's putative "safe harbor." 82

If notices are generally sent when copyright infringement is clear-cut - the assumption behind the positive story of the DMCASection 512 may represent an efficient way to clear infringing

78. Conference: Franklin Pierce Law Center's Seventh Biennial Intellectual Property System Major Problems Conference Digital Technology and Copyright: A Threat or a Promise? 39 IDEA 291 (1999).

79. Section 512(f). See also, Conference: Franklin Pierce Law Center's Seventh Biennial Intellectual Property System Major Problems Conference Digital Technology and Copyright: A Threat or a Promise? 39 IDEA 291 (1999).

80. The watershed case that came down prior to the passage of $\S 512$ is Religious Tech. Ctr. v. Netcom On-Line Communication Servs., Inc., 907 F. Supp. 1361 (N.D. Cal. 1995). The court in this case said that an online service provider could be held liable for its users' infringement if it had notice of the infringement and materially contributed to it. It is not entirely clear that the caselaw would have continued to develop in this direction, though the $\S 512$ takedown procedures seem to assume a duty on the part of hosting and search OSPs.

81. Alfred C. Yen. Internet Service Provider Liability for Subscriber Copyright Infringement, Enterprise Liability, and the First Amendment. 88 GEO. L.J. 1833 at 1888 (2000).

82. TicketMaster Corp. v. Tickets.com, Inc., No. CV 99-7654 HLH(BQRX), 2000 WL 525390 (C.D. Cal. Mar. 27, 2000) (even deep-linking did not violate copyright law, because source was clear); Bernstein v. J.C. Penny, Inc., No. 98-2958 R EX, 1998 WL 906644 (C.D. Cal. Sept. 29, 1998) (linking to a site that linked to another site containing infringing materials did not constitute contributory infringement). But see Intellectual Reserve, Inc. v. Utah Lighthouse Ministry, 75 F. Supp. 2d 1290 (D. Utah 1999) (hyperlinks were infringing). 
materials from the Internet. If this is the case, then shifting the burden to alleged infringers and costs to OSPs may represent a useful compromise, and the incentives for OSPs to err on the side of takedown will be less troubling. On the other hand, if notices are sent when copyright infringement is alleged but unclear, or defective notices are the norm - the assumption behind the negative view of the DMCA-Section 512 may represent a wolf in sheep's clothing, allowing First Amendment-protected expression to be removed from the Internet cheaply, expeditiously, and without check.

With these competing visions of the DMCA in mind, we conducted a study of $\S 512$ takedown notices. We hoped to begin describing in general terms how the $\S 512$ process is being used. Additionally, we hoped to find out whether its use to date (at least as reflected by our data) best supports the positive view or the negative one.

\section{The Study: The Chilling EfFects Project and Data SeT}

Studying the uses of the $\S 512$ notice-and-takedown procedure poses challenges, since it involves only private party action-ceaseand-desist letters - and no public record-keeping. We have, however, developed a data set through the Chilling Effects project, which collects, annotates, and publishes cease-and-desist letters related to Internet expression. ${ }^{83}$ The Chilling Effects project consists of a consortium of law school clinics and the Electronic Frontier Foundation; and since January 2002, the project has collected ceaseand-desist letters on a variety of intellectual property and other online-speech-related doctrines such as defamation. Students and faculty (including the authors, at various times) at the Samuelson Law, Technology \& Public Policy Clinic, University of California, Berkeley, have reviewed and annotated $\S 512$ notices for the site.

Our present data set includes 876 notices submitted to Chilling Effects through August 2005. We have generally split this into two effective data sets for statistical analysis. First, the project includes all notices submitted to Google Inc., since March 2002, (734 notices as of August 2005), which we refer to throughout as "Google" notices. Second, the project also includes self-reported notices submitted, usually by recipients, to Chilling Effects through online web forms (142 notices), which we refer to throughout as "self-reported" or "non-Google" notices, as appropriate. See Fig. 1.

83. See Chilling Effects, http://chillingeffects.org/. 


\section{Data Set by Section}

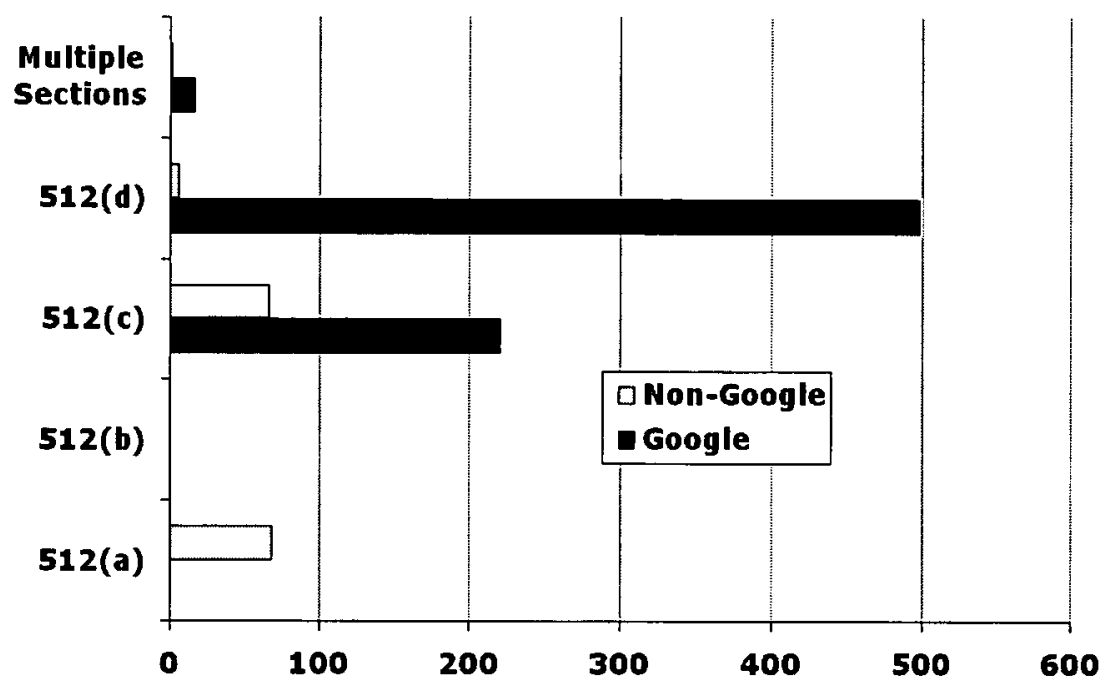

Fig. 1. The Chilling Effects § 512 data set, broken down by DMCA Section and recipient OSP (Google and NonGoogle OSPs).

The data set is subject to two obvious limitations. First, notices from Google-a single company-constitute $84 \%$ of the entire set; further, two-thirds of the Google data are related to search services, rather than hosting. This predominance of search notices skews the entire set toward characteristics of search index takedowns. The Google data set, however, is very robust in that it contains all notices received by Google over the observed time period; as such, it provides a complete picture of a major online service provider's interaction with $\S 512$.

A second significant limitation is that the other set of noticesthe set of "non-Google" notices-is relatively small, and largely individually self-reported. As such, these notices may skew towards the substantively flawed; it seems plausible that individuals who have a strong defense (or at least believe there is a strong defense) are more likely to submit their notices to the Chilling Effects database. ${ }^{84} \mathrm{We}$

84. The Chilling Effects project makes no determination on the merit of any notice, and publishes all notices regardless of whether they are problematic. Just the same, the very name of the site may lead people to over-report problematic notices. In any case, it seems probable that 
approached these notices cautiously; however, a third of the notices from Google relate to hosted material, rather than search index links. This gives us a non-self-selected group of notices related to hosted material, although, again, a group limited to one company. We make allowances for these flaws by separating the two sets in most analyses. Additionally, we note places where our findings may be limited by the vagaries of the set. Fortunately, the Chilling Effects project has also obtained an additional set of more than 1600 notices received by The Planet, a Texas-based web host and access ISP, from September 15, 2004 to the present. For near-future research, the data set from The Planet will be very important for checking conclusions and comparing search engine and self-reported data with a complete set from a hosting service.

\section{A Note ON METHODOLOGY}

In order to obtain the detailed picture of the process we desired, we needed to evaluate each notice, at least briefly, based on its complaints and the underlying facts, in addition to recording basic information about the senders, recipients, targets, etc. For this reason, we repeatedly encountered a critical component of copyright law: its fact-specific nature. Copyrightability, infringement, and fair use are all analyses that are subject to change, depending on the person analyzing the case. For this reason, there was no way to avoid judgment calls when coding notices for substantive legal flaws, but we attempted to limit any issues by conservatively classifying notices and by using multiple reviewers for each notice, as well as using a coding worksheet with detailed guidelines for coding. After each notice had been reviewed at least twice, one of the authors went back through to check that reviewers had converged on a common approach to coding.

Fair use is notoriously difficult to define, so we approached it carefully. We coded notices for favored use, such as parody, news, commentary and reporting. We avoided fair use claims that would rely only on the small amount of copying (though we did include noncopyrightable snippets such as titles in our substantively-flawed set). We looked particularly at the transformativeness, the purpose, and the commerciality of the use, and steered clear of counting many arguable or borderline fair uses. We took a similarly conservative approach to other substantive flaws, such as non-copyrightable subject matter. For 
example, we coded notices citing purely factual matter or noncopyrightable systems or methods, such as recipes or statistical methodologies as "noncopyrightable subject matter." But we chose not to code for noncopyrightable subject matter unless the subject matter plainly represented such a question. For instance, numerous notices alleged copyright infringement of "website design" or "layout," which certainly raise possible defenses along the lines of copyrightability. However, we did not code such notices as noncopyrightable subject matter.

We also sorted senders and recipients into various categories, such as "hobbyist" or "competitor," terms which are subject to definitional judgment calls. Again, we took care not to stray from fairly conservative characterizations of these categories. A party classed as a "competitor" generally is in the same, or a very closely related, business as the adverse party. "Hobbyists" include bloggers, fan sites and the like.

Notices were stored in a MySQL database, and coded according to the attributes described below. In addition, some attributes were tagged via keywords. We extracted information from the database using queries on both the coded attributes and the keyword tags.

\section{OBSERVATIONS}

\section{A. General Observations}

The overall set of 876 cease-and-desist notices includes 514 notices (59\%) making a complaint only under $§ 512(d)$ (search engine index link); and 315 notices (36\%) making a complaint only under $\S 512$ (c) (hosted material). In addition, $68 \S 512$ (c)-like notices were sent to OSPs complaining of material residing on a user's computer. In other words, these notices ask for "takedown" in a situation where $\S 512(\mathrm{a})$ - the straight safe harbor for routing and communicationslikely actually applies. ${ }^{85} \mathrm{~A}$ few notices $(22$, or $3 \%$ ) included claims

85. Parenthetically, we note that under our analysis, the data set includes no notices that reference $\S 512$ (b), although 16 notices mention Google's search index cache. In our analysis, we had determined that Google's search engine cache was not covered by $\$ 512(\mathrm{~b})$; see supra note 11 for our reasoning. Two recent District Court decisions, however, indicate towards reanalysis of the current dataset with respect to $\$ 512(\mathrm{~b})$ claims. Blake A. Field v. Google Inc., NO. CV-S-04-0413-RCJ-LRL, 2006 U.S. Dist. LEXIS 10923, (D. Nev. Jan. 12, 2006); Gordon Roy Parker v. Google, Inc., Civil Action No. 04-CV-3918, 2006 WL 680916 (E.D.Pa. March 10, 2006). The Blake A. Field court found that Google received a $\$ 512(\mathrm{~b})$ safe harbor for its search engine cache. Given our thinking when undertaking the study, we had concluded that the dearth of apparent $\S 512$ (b) notices in our dataset suggested that the technically-detailed 
under more than one statutory section. Of the $514 \S 512(\mathrm{~d})$ search engine claims, only a few were sent to search engines other than Google. The vast majority of these notices were sent to Google solely, and a few were sent to multiple OSPs including Google. The high incidence of $\S 512$ (d) claims is, of course, due to the predominance of notices to Google in our data set. While Google submits all of its notices to Chilling Effects, two-thirds of its notices are for its search engine listings. Google-provided hosting services-including Blogger, UseNet and Google Groups archives-account for about a third of Google's total notices. ${ }^{86}$ See Fig. 1, above.

\section{Google Notices: General Observations}

We first note that there has been an increase over time in notices sent to Google, but that we cannot reliably tell from our data whether this represents a continuing upward trend. Section 512(c) and (d) notices both increased in the Google set from 2002 to 2005. See Fig. 2. In the somewhat more than three years' worth of data that we evaluated, the total number of $\S 512$ (c) and (d) notices submitted to the database increased from 70 in 2002 (March-December); to 151 notices in 2003; to 253 notices in 2004; to 245 in just the first seven months of 2005 .

$\S 512$ (b) provision was little used by either complainants or OSPs. However, should the Field and Parker interpretation of $\S 512$ (b) carry the day, then that provision will indeed provide an important protection for OSPs. Therefore, we will likely be revising our metric with respect to $\S 512(\mathrm{~b})$, and re-analyzing the current dataset as well as examining the dataset from The Planet for any relevant notices.

86. We have assumed that Usenet postings residing on an ISP's server are an instance of $\S 512$ (c) services. However, at least one case analyzed them as a $\$ 512$ (a) service. Ellison v. Robertson, 357 F.3d 1072 (9th Cir. 2004), 189 F. Supp. 2d 1051 (C.D. Cal. 2002). See generally Sean Croman, Where the Netcom Yardstick Comes Up Short: Courts Should Not Apply the Facts of Netcom as an Example of Intermediate_and Transient Storage Under \$5I2(a) of the DMCA, 80 WASH. L. REV. 417 (2005) (discussing this inconsistency, and arguing that Usenet hosts should be considered $\S 512$ (c) providers). We agree. 


\section{Google Notices, 512(c) and 512(d) Compared, March 2002 - July 2005}

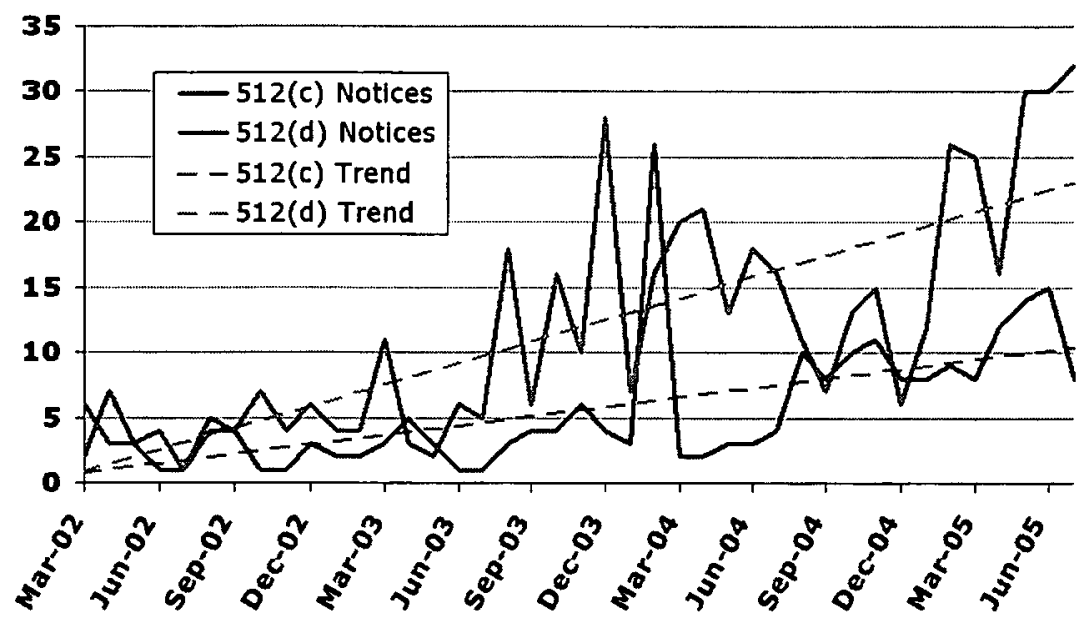

Fig. 2. Section 512(c) and 512(d) notices being sent to Google.

We had expected that some of the increase in total numbers of notices would have come through growth in visibility and awareness of the Chilling Effects project itself, but on examining the data it became apparent that most of the growth has come thus far from an increase in actual notices submitted to Google during the period in question. The number of notices actually sent and received by Google over almost the same period of time (April 2002-June 2005) has increased from an average of four per month in 2002 to eighteen per month for the first six months of 2005.87 However, it was impossible to confidently determine whether there is a forward trend in the

87. We began counting Chilling Effects submissions in January 2002. While Chilling Effects officially opened in February, coordinators had already begun collecting notices. The Google submissions began in March 2002, and Google-only tables and Google-comparison tables date from March 2002. For timeline and trendline purposes, we cut off analysis of both sets of data with July 2002, which was the last month that seemed relatively complete. The Chilling Effects database is a live database, which means that its data set changes over time. A user may decide in 2006 to submit a notice or series of notices that they received years earlier. Such data, while they may not be statistically significant, are still useful in terms of anecdotal evidence of usage. Moreover, if a large set of older data is suddenly deposited and analyzed, the statistical picture could change. For this reason, we have chosen to be careful with our analyses of the significance of pieces of the data set. 
data. ${ }^{88}$ (Though the chart visually appears to show an increasing trend, the R-squared values for the lines of best fit reveal (1) that the seeming increase is only weakly predictive for $\$ 512(d)$ notices $\left(R^{2}=\right.$ 0.60 ); and (2) that we cannot predict with confidence whether the 512(c) notices will increase over time, at all $\left(\mathrm{R}^{2}=0.33\right)$.) Further, without a broader set of notices than we have, it is obviously impossible to determine whether use of the $\S 512$ process generally is increasing or not.

The $\S 512(d)$ search engine notices do appear to have increased more dramatically than the $\S 512(\mathrm{c})$ hosted content notices sent to Google, and there is, overall, a much greater volume of $\S 512$ (d) notices in the set. This is true even though Google increased its $\S 512$ (c) offerings steadily during the study period. ${ }^{89}$ Of the increases in $\S 512$ notices noted in the Google set and accordingly in the set of notices as a whole, it is plain that most are $\S 512(d)$ notices. See Figs. 2 and 3. The set of $\S 512$ (d) notices sent to Google has increased from an average of three notices per month in the second and third quarters of 2002 , to an average of 21 per month in the second quarter of 2005.90

Whether considered separately by OSP, section, or as a whole, the number of notices collected during any given month is small enough - 5 to 45 notices - that a single spate of notices from an aggrieved user can cause a notable spike in the set. In February 2004, for instance, the American Poolplayers Association sent twenty notices to Google for UseNet archives, creating a visible spike in the $\S 512$ (c) collection. See Figs. 2 and 3. Likewise, just two months prior, in December of 2003, Mir Internet Marketing sent eighteen notices to Google, spiking the $\S 512(d)$ data set. This wide variability

88. The period of time we have so far is relatively small (less than four years), the overall numbers received are small, and the numbers received in any given period of time vary significantly, resulting in very different standard deviations across almost any period of time we examined.

89. Online forums of various sorts continue to grow in kind and number, and Google has moved into these markets, both old and new. In 2001, Google took over Deja.com's UseNet Discussion Service UseNet archives, maintaining them as Google Groups. In addition to UseNet feeds, Google Groups users can establish their own discussion groups, hosted by Google, and maintained in the Google Groups hierarchy. In 2003, Google purchased Blogger, which provides Blog*spot services, one of the major free bloghosts. See Elise Bauer, An Overview of the Weblog Tools Market, Aug. 6, 2004,

http://www.elise.com/web/a/an_overview_of_the_weblog_tools_market.php and Elise Bauer, Feb. 15, 2005, Weblog Tools Market - Update February 2005, http://www.elise.com/web/a/weblog_tools_market_update_february_2005.php.

90. The standard deviation varied significantly, making it difficult to determine any trend. 
month-to-month is obvious from Fig. 2, and shown in more detail in Fig. 3.

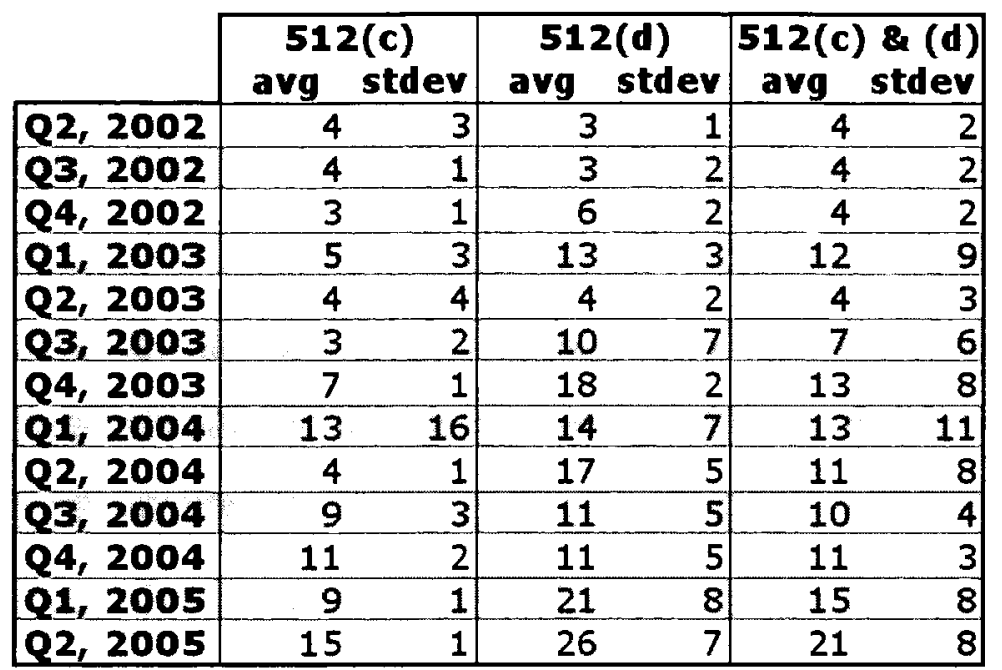

Fig. 3. Notices to Google, monthly averages per quarter, April 2002June 2005.

The preliminary data from The Planet is not yet extensive enough to fully determine trends, or compare with the other notices. We note, however, that The Planet receives many more notices monthly than Google, and so will provide a rich sample of data to review for trends in future work, particularly over longer periods of time than we have yet been able to observe. ${ }^{91}$ See Fig. 4.

91. The data from The Planet is only approximate at this point. We receive the notices in batches and detailed analysis is needed to truly gauge how many notices are received daily. Consequently, the very rough data set we currently have is broken down only into monthly totals, which still show significant fluctuations month-to-month, ranging from a low of 79 received in September 2004 to a high of 207 notices received May 2005. We also note that the averages and totals may be artificially suppressed by the last month of data, which is likely not complete. In this early analysis, we left August of 2005 in the calculations, although we are aware that some additional notices dated from that month might subsequently arrive. 
ThePlanet - Monthly Notice Totals,

September 2004 to August 2005

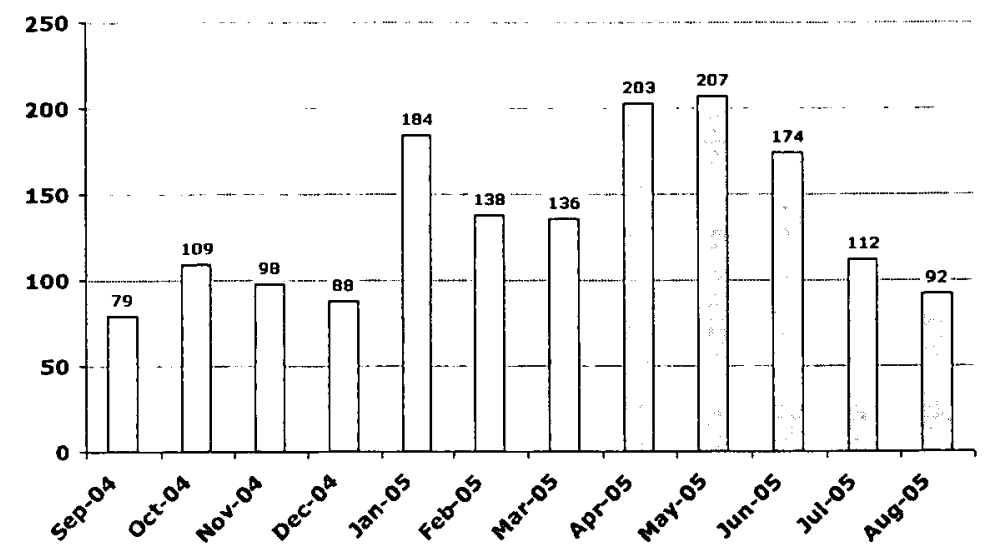

Fig. 4. Numbers of notices sent to The Planet, Sept. 2004-Aug. 2005.

\section{Self-reported Notices; General Observations}

We also examined the self-reported set of notices. Here we note that nearly half the notices were sent in response to a situation where $\S 512$ (a) would likely apply-largely situations where alleged infringers are trading files across peer-to-peer networks. Fig. 1, above. In fact, $\S 512(\mathrm{a})$ establishes a straightforward safe harbor for OSPs acting as conduits, with no notice-and-takedown procedure. Further, because complained-of files reside on user machines, the OSP cannot take down the material in the first place. In instances where the user is engaged in simple distribution of entire copyrighted works, we may presume that the underlying copyright complaint is strong, although defenses, such as the misidentification of the alleged infringer, may certainly apply. However, because $\S 512$ (a) does not authorize takedown notices, these notices raise other issues. We discuss this result further below.

\section{B. Sender Characteristics}

We examined the characteristics of those using the $\S 512$ processes in our data set.

\section{Corporate Senders}

In our data set, corporations and business entities were the primary users of the $\S 512(\mathrm{c})$ (hosting) and $\S 512(\mathrm{~d})$ (search) 
processes, and the primary senders of notices related to $\S 512(\mathrm{a})$ services (64 notices, 94\%). ${ }^{92}$ Fig. 5. Of Google $\S 512(\mathrm{c}$ ) notices, corporate and business senders made up $72 \%$ (171 notices) of the senders.93 Among self-reported $\S 512(\mathrm{c})$ notices, corporate and business senders made up $65 \%$ of notices. ${ }^{94}$ Among $\S 512(\mathrm{~d})$ notices, the large majority, $409(79 \%)$, were sent on behalf of corporate or business entities. 95

\section{Who Sends $\$ 512$ Notices}

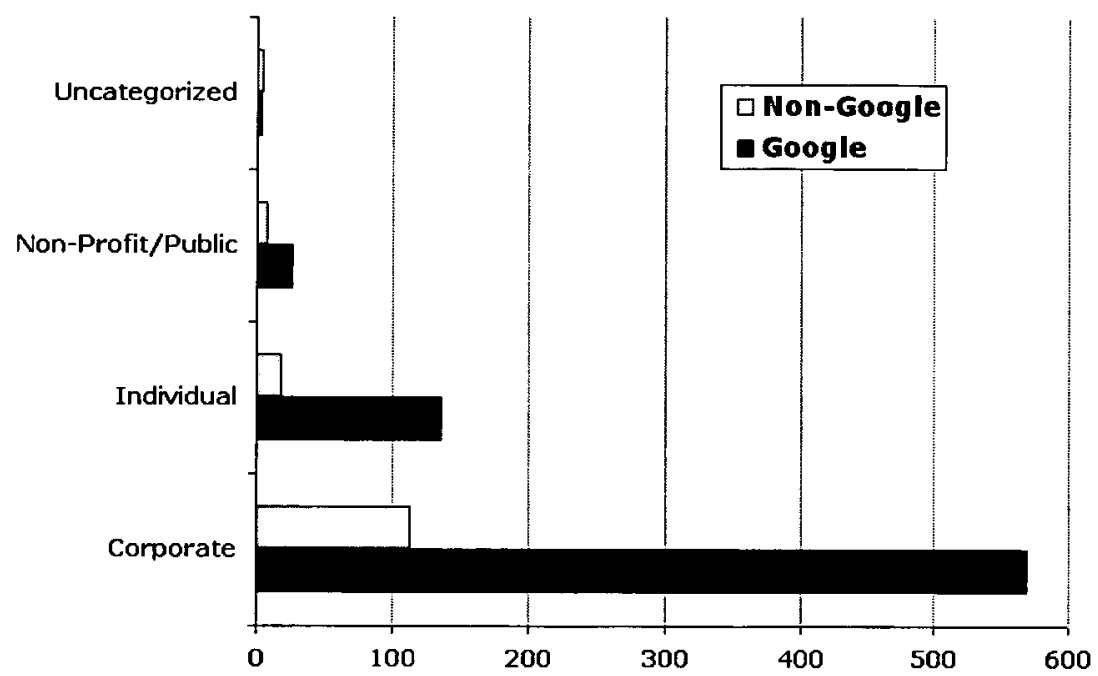

Fig. 5. Categories of $\$ 512$ Complainants.

Beyond the general fact that business entities sent the large majority of notices, there were some interesting specifics. Section 512(c) and (d) senders in our data set are often small Internet

92. Apparent non-profit/public interest entities also sent a minority of the notices. 15 of 236 Google $\S 512$ (c) notices (6.3\%) were apparently sent by or on behalf of non-profit or public interest organizations. Google received $12(2.3 \%)$ of its $\S 512(\mathrm{~d})$ notices from or on behalf of apparent non-profit or public interest entities. Additionally, 7 self-reported $\S 512$ (c) notices $(10.2 \%)$ were sent by or on behalf of nonprofit or public interest entities.

93. Some notices had more than one sender, and some senders could not be classified. The set of senders of Google $\S 512$ (c) notices was $236 ; 171$ were sent by corporations and business entities.

94. Some notices had more than one sender, and some senders could not be classified. The set of senders of self-reported $\S 512$ (c) notices was $68 ; 44$ were sent by corporations and business entities.

95. All six of the self-reported $\S 512$ (d) notices were sent by corporations and business entities. 
businesses. A large percentage of Google search notices-55\% of the Google $\S 512(\mathrm{~d})$ notices-are competition-related.96 Entities send these notices to request the removal of links to their competitors. ${ }^{97}$ (This phenomenon is discussed further, below.) The software and game industries sent $23 \%$ of the $\S 512$ (c) notices (70 unique notices). These were largely related to circumvention of technological protection measures; 98 a significant percentage included other claims of questionable relevance to the $\S 512$ takedown procedures, including license restrictions, resales, game "cheats," and the like.

Perhaps surprisingly, neither $\S 512(d)$ search nor $\S 512(\mathrm{c})$ hosting notices in our data set show significant use by the movie and music industries. While, as noted supra in Section III, these industries anticipated and helped draft the notice and takedown provisions in $\S 512$ (c) and (d), our data show them only rarely using these provisions. Corporate and business entities are generally responsible for the lion's share of notices, but the movie and music industries combined were responsible for only $6 \%$ of the $\S 512$ (c) notices and only $3 \%$ of the $\S 512(\mathrm{~d})$ notices. The lack of entertainment companies in our set may be, at least in part, because they choose not to send search engine complaints; however, we suspect that is not the entire story.

While we did not see nearly the number of $\S 512(\mathrm{c})$ or (d) notices we expected from it, the movie industry (followed by the computer software and games, and then music, industries) sent the vast majority of $\S 512$ (a) "takedown notices"-where takedown is neither required nor possible, but where complaints about an alleged infringer might convince the OSP to terminate the alleged infringer's service-in our data set. Our data do not reflect the very high numbers (in the tens of thousands annually) of notices received by larger OSPs from the content industry, but the use of $\S 512$ (a) apparent in our very limited data has been anecdotally verified through a confidential interview discussing numbers from larger

96. See supra Section V for a description of the way we used the term "competitor."

97. A relatively high number, $35 \%$, of Google notices are coded "unclassifiable" or "no information" with respect to sender characteristics. This is because $\S 512$ notices do not always contain a great deal of detail. Given this, it may be that percentages are not entirely accurate across the data set.

98. Illegal circumvention, by itself, is not properly the subject of a $\$ 512$ notice, at least according to one court. Universal City Studios, Inc. v. Reimerdes, 82 F. Supp. 2d 211, 217 (S.D.N.Y. 2000) ("Section 512(c) provides protection only from liability for copyright infringement. Plaintiffs seek to hold defendants liable not for copyright infringement, but for a violation of Section 1201(a)(2), which applies only to circumvention products and technologies. Section 512(c) thus does not apply here.") (intemal citations omitted). 
OSPs, among other sources. ${ }^{99}$ We look forward to examining this empirically with data from The Planet. If this $\S 512$ (a) effect is borne out, it seems likely that complaints about infringing movies and songs now focus on peer-to-peer networks, where the OSP acts only as a conduit. This change (unanticipated when the statute was drafted and passed) might help explain the relatively few copyright industry $\S 512$ (c) and (d) notices we collected. If true, this suggests that the copyright industry's concerns about piracy are currently not welladdressed by the notice-and-takedown process.

\section{Individual Senders}

Individuals constitute a significant minority of all senders in both the $\S 512(\mathrm{c})$ and $\S 512(\mathrm{~d})$ contexts. Of Google $\S 512(\mathrm{c})$ notices, $20.7 \%$ of notices are apparently sent by, or on behalf of, individual rights-holders (49 of 236). Among non-Google $\S 512$ (c) notices, 17 $(25 \%)$ were sent by or on behalf of apparent individuals. The situation is not markedly different among senders of $\S 512(\mathrm{~d})$ notices. Google received $92(17.9 \%)$ of its $\S 512(\mathrm{~d})$ notices from, or on behalf of, individuals.

As might be expected, complaints sent on behalf of individuals vary considerably; it would be difficult to describe a "typical" complaint. For example, one individual complainant cited a blogger who had repeatedly re-posted entire posts without crediting the original author. ${ }^{100}$ Another individual wrote to request the removal of a book cover from a review site (the review, we note, was critical). 101 Another complaint was apparently from a person unhappy with the

99. Confidential interview. See also Pleadings, Pacific Bell Internet Services v. RIAA, No. C 03-3560 SI, (N.D. Cal. Nov. 26, 2003) (Source on file with Author). In 2002, Pacific Bell Internet Services and its affiliates received more than 16,700 notices from MediaForce alone. Greg Wrenn, Associate General Counsel for Yahoo!, Inc., reported similarly high volumes, of several thousand notices each calendar quarter. A Look Back at the Notice-Takedown Provisions of the U.S. Digital Millennium Copyright Act One Year After Enactment, WIPO Workshop on Service Provider Liability, Dec. 1, 1999. The Yahoo! notices, however, are likely a mix of \$512(a), (c), and (d) notices. We note that at that time, Mr. Wrenn observed that few users used the counter-notification procedures. He estimated that at that time, $5 \%$ of notices were "shams" using the system to silence or harass critics, citing the Scientologists. Our data suggest to us that many notices exhibit substantive problems beyond obvious cases of attempts to silence or harass critics.

100. Notice \# 1046, http://chillingeffects.org/dmca512/notice.cgi?NoticelD=1046 (dated Jan. 9, 2004). The same complainant later filed a similar complaint against a different party. Notice \# 1442, http://chillingeffects.org/dmca512/notice.cgi?NoticelD=1042 (dated Sept. 20, 2004).

101. Notice \# 1362 http://chillingeffects.org/dmca512/notice.cgi?NoticelD=1362 (dated July 1, 2004) (as of Oct. 2005, the book cover was still included with the review). 
use of his photograph on a website dedicated to criticizing his alleged disreputable character and dating habits. 102

\section{Repeat Senders}

A quarter of the senders in our database are repeat senders, and were responsible for more than half of all the notices. Of the 436 unique senders, $25 \%$ are repeat senders, and $329(75 \%)$ sent only one notice. In all, $547(62.4 \%)$ of the notices were sent by repeat senders 103 Within the $107(25 \%)$ of repeat senders, $86(20 \%)$ sent $2-5$ notices; $10(2 \%)$ sent 6 to 10 notices; six (1\%) sent 11 to 20 notices; and five senders ${ }^{104}(1 \%)$ sent more than 20 notices-ranging from 21 to 54 notices.

The relatively few senders that sent large batches of notices are a significant presence in the dataset (the top 11 senders sent $29 \%$ of the overall notices in the data set) and any problems with their notices can affect the overall conclusions. ${ }^{105} \mathrm{We}$ paid special attention, therefore, to issues with notices from those top senders. The American Poolplayers Association, which sent 21 notices, had a significant effect on the number of notices with questions about the copyrightability of the complained-of material. (APA's 21 notices comprise $57 \%$ of the 37 notices that presented obvious questions of copyrightability. See infra Sec. VI.F.) Microsoft's 21 notices all related to circumvention of software, of which 20 were $\S 512(\mathrm{c})$ notices, and one was apparently to a $\S 512(\mathrm{a})$ subscriber. ${ }^{106}$

102. Notice \#954, http://chillingeffects.org/dmca512/notice.cgi?NoticeID=954 (dated Nov. 11, 2003).

103. Although we have some idea of how many notices for which each repeat sender is responsible, we may not have captured all notices for each sender because senders may send under alternative or variant names. For instance, the Avatar / Star's Edge notices are listed under both names.

104. The top five senders in the database range widely. American Poolplayers Association and Microsoft Corp. sent 21 notices, and ArticleInsider.com/Infosearch sent 23 notices. Mir Internet Marketing sent 50 notices and Star's Edge, International/Avatar sent 54 notices.

105. We did not engage in detailed statistical manipulation to attempt to isolate the level of effect that repeat senders had on the overall results. We made this decision first, because our goal in this paper is to obtain a snapshot of the $\S 512$ process, and the fact that repeat senders send flawed notices is a useful part of that information. Second, because the present data are limited in the other ways described above, we would rather look at any repeat sender effect in more detail with a more broadly applicable data set. To this end, we hope that data from The Planet will be useful.

106. This notice was unpublished for reasons unrelated to its content. Though the vast majority of the notices that comprise our dataset are publicly available on the Chilling Effects website, a few notices are on file in the nonpublic database. Note that, throughout the Article, we generally cite notices illustratively, rather than comprehensively. Where there are three or fewer notices in a particular category we cite them all. 
ArticleInsider/Infosearch sent 23 notices, $7.2 \%$ of the literary properties in the $\$ 12$ (d) set. Mir Internet Marketing's 50 notices almost entirely (48) related obviously to competitors. Star's Edge/Avatar's 54 notices were not counted as fair uses as a per se rule, but were not excluded from the count if something specific to the notice warranted its inclusion.

\section{DMCA Enforcement Companies, Agents, Proxies \& Rightsholders}

We were interested in who executes the $\S 512$ process for complainants, given the existence of private "rights enforcement" companies. The vast majority of all $\S 512$ (c) and (d) notices in our data set were sent by the rightsholders themselves, or their attorneys; far fewer notices were sent by agents, proxies or trade associations. Of $\S 512(\mathrm{c})$ notices, $94 \%$ were sent by or on behalf of the rightsholders directly. Of $\S 512$ (d) notices, $98.5 \%$ were sent by or on behalf of the rightsholders directly. ${ }^{107}$ Agents, enforcement agencies, and trade associations combined only account for $4.9 \%$ of all $\S 512$ (c) notices, and only $1.3 \%$ of $\S 512(\mathrm{~d})$ notices. ${ }^{108}$ The picture is much more diverse in our $\S 512$ (a) notices, where rightsholders sent $29 \%$ of the notices; enforcement companies sent $26.1 \%$ of the notices; and trade associations sent $30.4 \%$ of the $69 \S 512(a)$ notices. 109 Of $\S 512$ (a) notices sent on behalf of the large entertainment corporations, 18 notices were sent by DMCA enforcement companies, prominently including BayTSP, GrayZone and MediaForce. ${ }^{110}$

Trade associations also show up as senders among our data, although they are a clear minority of users of the process. In total, 36 notices were sent by trade associations. Of the trade association notices, most represented corporate interests, such as the Business Software Association; only three represented individual interests, such as the Science Fiction Writers Association and the Creators

107. To the extent that the rightsholders are individuals, this is a testament to the ease and simplicity of the process. However, "rightsholder" encompasses any rightsholder, whether corporate, nonprofit, or individual.

108. A small number of notices in each category could not be classified as to their relation to the rightsholder. For instance, T-Mobile sent a notice on behalf of celebrity customer, Paris Hilton, regarding her T-Mobile address book which was apparently hacked. See notice \# 1761, http://chillingeffects.org/dmca512/notice.cgi?NoticeID=1761 (dated Mar. 15, 2005).

109. The remainder, 10 notices (14.5\%), were unclassifiable.

110. See Sonia Katyal, Privacy Vs. Piracy, 7 YALE J. L. \& TECH. 222 (2004-05), and The New Surveillance, 54 CASE W. RES. L. REV. 297 (2003) (discussing the privacy and surveillance concerns that arise from these enforcement agencies). 
Syndicate. 111 We note that the Recording Industry Association of America (RIAA) and the Motion Picture Association of America (MPAA) have only 9 notices in the $\S 512$ (c)-(d) sections, and that, to the extent that they used copyright enforcement agents such as MediaForce, they may appear under-represented. ${ }^{112}$ Only three notices were sent by traditional literary or licensing agents. In a few instances, celebrities or models' agencies and publishers collaborated to send notices. ${ }^{113}$

\section{Target Characteristics}

Examining the characteristics of the targets of the notices-the alleged infringers-we found that $41 \%$ of all Google notice targets can be classed as competitors of the complainants. Fig. 6. This is particularly significant for Google $\S 512$ (d) complaints regarding links in the index, where $55 \%$ of all notices relate to competitors. A significant percentage of the $\S 512(\mathrm{c})$ and (d) notices sent to Google-21\%-target hobbyists, critics and educational users.

The "hobbyists" category includes many bloggers and fan sites. Notices sent to hobbyists are often from rival hobbyists or businesses in the field. Unauthorized use of photographs or graphics is a common theme in these notices, especially in the blog-related notices. ${ }^{114}$ The blogs may or may not be directly related to the topic of the copyrighted work; a use may be simply an illustration, linked to

111. Notice \# 374, http://chillingeffects.org/dmca512/notice.cgi?NoticeID $=374$ (dated July 29, 2002); notice \# 402, http://chillingeffects. org/dmca512/notice.cgi?NoticeID $=402$ (dated Sept. 6,2002 ); and notice \# 408, http://chillingeffects.org/dmca512/notice.cgi?NoticeID $=408$ (dated Sept. 9, 2002).

112. We classed notices sent by trade associations as either "corporate" or "individual" senders based on their constituent members. We classed the Science Fiction Writers Association (SFWA) and the Creators Syndicate as "individual" senders because the associations primarily represent individual creators. We categorized other associations as "corporate" senders because they represent primarily corporate rightsholders. The "corporate" senders include the Recording Industry Association of America (RIAA), Motion Picture Association of America (MPAA), Interactive Digital Software Association (IDSA), Business Software Association (BSA), and Entertainment Software Association (ESA).

113. See, e.g., notice \# 1626, http://chillingeffects.org/dmca512/notice.cgi?NoticeID=1626 (dated Jan. 11, 2005); notice \# 1456, http://chillingeffects.org/dmca512/notice.cgi?NoticelD=1456 (dated Sept. 15, 2004).

114. See, e.g., notice \#968, http://chillingeffects.org/dmca512/notice.cgi?NoticelD=968 (dated Nov. 11, 2003) (photographs of the "Merry Pranksters" used on the "Cosmic Baseball Association" website, a "baseball league of the imagination."). 
or grabbed from the Internet for its aesthetics rather than its original significance. 115

Target Characteristics Google 512(c) vs. Google 512(d)

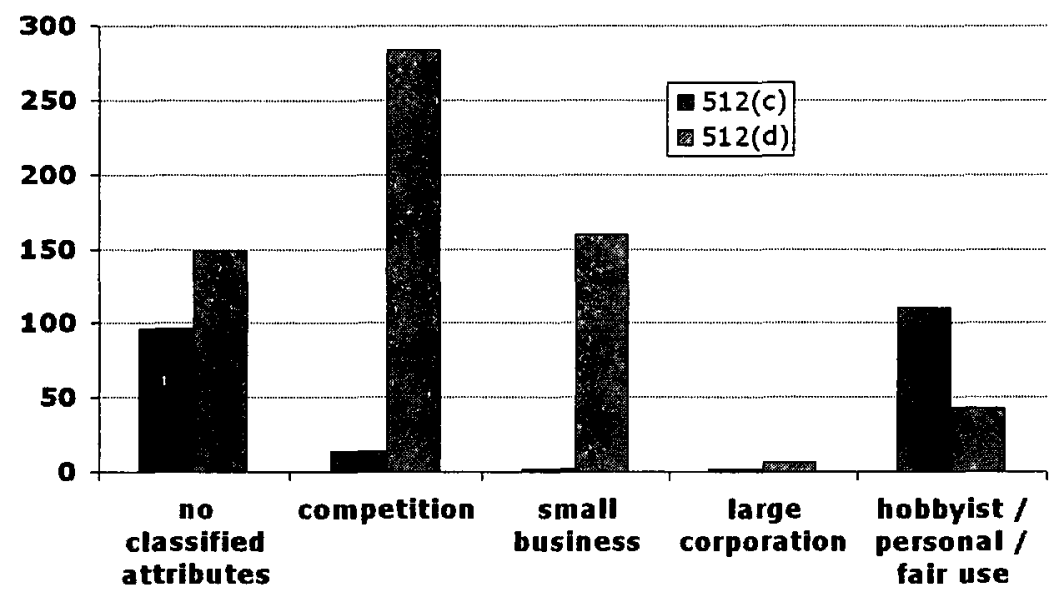

Fig. 6. Characteristics of targets of $\$ 512(c)$ and (d) notices sent to Google.

Comparison with the self-reported notices-including $\S 512(a)$ notices-shows that notices sent about competition are far more significant in the Google set than the self-reported set, and are particularly significant for search index complaints. This is unsurprising, given the fierce competition over search-result rank in Google's index. The hobbyists, critics and educational uses are higher in the self-reported set, also perhaps unsurprising given the selfselecting nature of that set. Fig. 7 .

115. See, e.g, notice \# 2189, http://chillingeffects.org/dmca512/notice.cgi?NoticeID=2189 (dated July 28,2005 ) (takedown notice regarding a photo of a poodle, used by a blogger to illustrate an original poem); notice \# 1287 ,

http://chillingeffects.org/dmca512/notice.cgi?NoticeID=1287 (dated May 14, 2004) (a blog for Columbia students apparently linked to a graphic on the complainant's website). 
Target Characteristics (Google vs. non-Google OSPs)

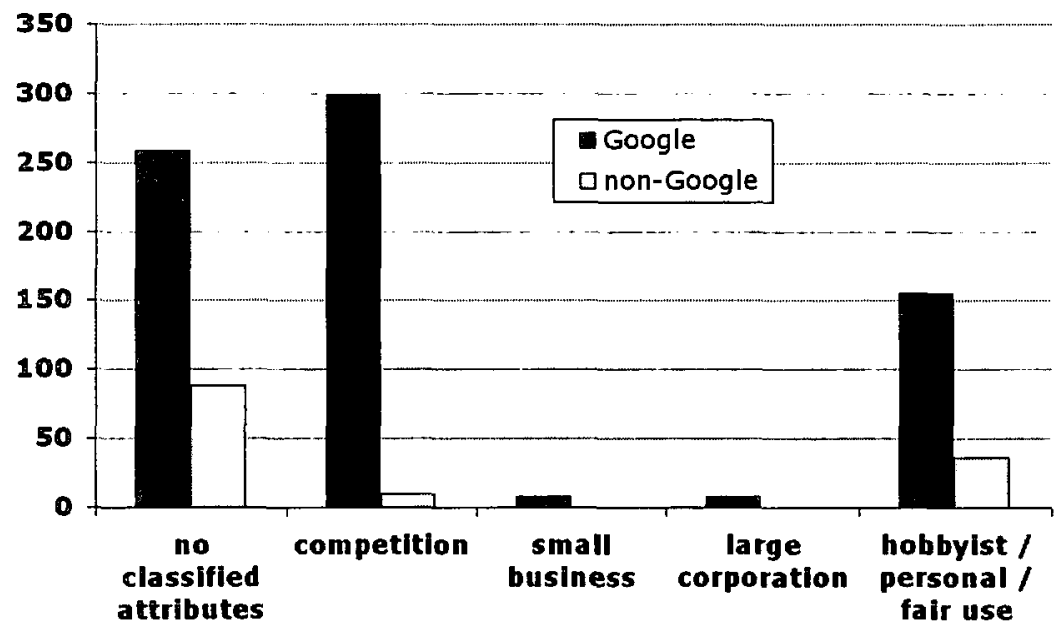

Fig. 7. Characteristics of targets of $\$ 512$ notices.

\section{Recipient OSP Characteristics}

The data set of self-submitted notices is too small to afford any real quantitative analysis of recipient OSP characteristics. However, we do note that the notices represent many different kinds of OSPs. 116 A wide variety of hosting providers are represented, including blog hosts (LiveJournal and Blogger, a Google subsidiary), and UseNet hosts (Google Groups submits posts).117 Section 512(a)-type hosts include many broadband providers of both DSL and cable access. ${ }^{118}$ We also have at least one notice to an upstream host of a webhost. ${ }^{119}$

116. See supra note 85 , discussion of $\S 512(b)$.

117. One area of hosting services that we have yet to see significant notices for are the social networking services-Friendster, Tribe, MySpace, etc. Although Google has an entry in this marketplace, the Orkut (beta) service, its share in the social networking software market is relatively small. In the dataset as a whole, only one $\$ 512(\mathrm{c})$ notices pertain to social networking software-neither of them for Google's Orkut. Notice \#2219, (note available upon request from SaNTA Clara COMPUTER \& High TECH. L.J.) (dated Aug. 4, 2005, sent to MySpace.com).

118. The layering of services presents a potentially wide choice of $\S 512$ (a), (c), and (d) hosts for any given website. For instance, an individual who maintains a website may in fact have several "Internet Service Providers" in $\$ 512(\mathrm{c})$ and $\$ 512(\mathrm{a})$ capacities. The website may be on a "shared host" environment; essentially, space on a machine that is leased to the website owner. The lessor may in turn be a lessee of another company, and there can be several layers of this kind of webhost. Each of these would be $\S 512(\mathrm{c})$ providers. Ultimately, the machine is 


\section{E. Subject Matter: Characteristics of the Allegedly Infringing Material}

In this section, we delve into some more detailed characteristics of the notices we observed. For descriptive purposes, we sorted notices, and discuss them, according to loose subject matter categories, such as "text," "photographs" and "film." At some points, we use more detailed descriptors, such as "literary property." Although these categories can be, we think, useful in sketching a picture of the notices as a group, they are mainly descriptive, and we recognize that others may have sorted some notices differently.

\section{512(c) (Hosted Material) Notices.}

Out of all $\S 512(\mathrm{c})$ notices in either the Google or self-reported sets (303 in total), 10 relate to movies; 1207 to music; 1217 to games; $^{122} 63$ to software ${ }^{123} ; 37$ to photos; ${ }^{124} 8$ to other graphics; $; 25$ 166 to text; 5 relate to whole websites;127 and 4 were undefinable. ${ }^{128}$

Looking at the seven $\S 512$ (c) notices sent in reference to music more closely, we first note that all seven were self-submitted notices. Three of the seven requested takedown of music files being offered for download-one Faith Hill promotional song, another notice requesting takedown of multiple Faith Hill songs, and a third notice requesting takedown of some 88 songs by Ten Thousand Fists. 129 The other notices were a grab-bag. One notice was a complaint about music files offered, but listed the number of such files available as

owned and perhaps managed by another webhost, also a $\S 512$ (c) provider. That provider receives Internet access from a $\S 512$ (a) provider. If the website manager provides a bulletin board or other interactive service on the website, then the website manager may also act as a $\S 512$ (c) provider. If the website manager also maintains a search engine, then the website manager may also qualify as a $\S 512$ (d) provider.

119. Notice \# 500, http://chillingeffects.org/dmca512/notice.cgi?NoticeID=500 (dated Dec.

3,2002 ) (Dow Chemical to Verio, the upstream Internet provider for the Yes Men's webhost).

120. $3.3 \% ; 2$ Google, 8 non-Google.

121. $2.3 \%$; all 7 are non-Google.

122. $2.3 \% ; 2$ Google, 5 non-Google.

123. $20.8 \% ; 60$ Google, 3 non-Google.

124. $12.2 \% ; 22$ Google; 15 non-Google.

125. $2.6 \%$; 5 Google, 3 non-Google.

126. $54.8 \%$; 142 Google, 24 non-Google.

127. $1.7 \% ; 2$ Google, 3 non-Google.

128. $1.3 \% ; 2$ Google, 2 non-Google. Note that these percentages do not quite add up to $100 \%$, because four notices listed multiple types of content.

129. Notices \# 2102, 2113, 2246 (notices available upon request from SANTA ClaRA COMPUTER \& HIGH TECH. L.J.) respectively. 
"0."130 One notice requested takedown of guitar tabs, which are arguably fair uses; however, taking a fairly conservative approach, we did not code them as such. ${ }^{131}$ Two relate to celebrated cases of mashups or other claims of infringement of the derivative-works right: the Grey Album, ${ }^{132}$ or Beatallica. ${ }^{133}$ This is obviously far too small a sample to be statistically relevant, and almost certainly reflects selection bias relating to media coverage of the relevant subject matter. Increased media coverage may cause more people to download, and to host, the allegedly infringing material, both attracting cease-and-desist letters and also making it more likely that those letters will be submitted to Chilling Effects. For example, the Grey Album was the subject of a concerted "civil disobedience" day, which encouraged users to download and host the work, a mash-up of The Beatles' White Album and JayZ's Black Album. ${ }^{134}$ (Similarly, there was a concerted effort aimed at distributing and hosting the Diebold memos, a set of internal memos revealing practices that may have affected electronic voting machines. ${ }^{135}$ )

Of the ten $\S 512(\mathrm{c})$ notices sent by companies in the film industry, only two were sent to Google; the other eight were sent to other ISPs, and were included in the self-reported $\S 512$ (c) set. Of the

130. Notice \# 646, http://chillingeffects.org/dmca512/notice.cgi?NoticeID=646 (dated May $8,2003)$.

131. Notice \# 170, http://chillingeffects.org/dmca512/notice.cgi?NoticelD=170. The site was removed when we examined it but the original annotator noted that the contents were guitar tabs. Guitar tabs are often derived by a listener, and the entabulation process can result in different tabs from user to user. Entabulation is thus somewhat akin to a transcription of the music, but the transcriber has additionally made assessments about how the notes might best be played on a guitar. (Thanks to Robert Clarida for explaining the entabulation process).

132. Notice \# 858, http://chillingeffects.org/dmca512/notice.cgi? NoticeID=858.

133. Notice \# 856 (notice available upon request from author).

134. Grey Tuesday was Feb. 23, 2004. See Grey Tuesday, http://www.greytuesday.org/ (last visited Apr. 6, 2006).

135. One site chronicles the "electronic civil disobedience" story, and includes statements from participating protesters, like the statement from Micah White, student, Swarthmore College, on Oct. 29, 2003:

Diebold can't win! Each takedown request is simply met with more mirrors. We are willing and able to continue this campaign until the 2004 presidential elections. ... We estimate that at least 30,000 people have downloaded the entire collection of 13,000 memos directly from just three of the mirrors above. The memos are on peer-to-peer file trading systems. They are in Freenet.

Why War?, Targeting Diebold with Electronic Civil Disobedience, http://www.whywar.com/features/2003/10/diebold.html. See also Free Culture Swarthmore, History, http://scdc.sces.swarthmore.edu/history.html. 
two Google notices, one was a movie script, ${ }^{136}$ and the other cited trademark and copyright complaints about a Google blog, but without specifying any particular copyrighted or infringing works. ${ }^{137}$ Of the eight self-reported notices, we first note that two presented obvious defenses: one was a complaint about a screenshot ${ }^{138}$ and one was a misguided complaint about a public domain film archived at the Internet Archive. ${ }^{139}$ Three of the ten notices complained of illegal offerings of copyrighted content, all presumably popular TV shows. ${ }^{140}$ Although two notices were likely related to DeCSS claims, we did not include them in the anti-circumvention counts for lack of adequate confirming information. ${ }^{141}$ Finally, one notice was sent from IO/Titan Media to Sharman, notifying it that P2P users were using Sharman's software to distribute Titan's copyrighted films. ${ }^{142}$ Obviously, the self-submitted notices constitute a grab-bag of issues, and are likely not representative of all such $\S 512(\mathrm{c})$ notices.

As might be expected since the web is still heavily text-based in its offerings, text was by far the most-represented subject matter in the $\S 512(\mathrm{c})$ notices: $142 \S 512(\mathrm{c})$ notices relating to text were sent to Google, and $24 \S 512$ (c) notices relating to text were sent to selfreported OSPs and self-submitted by recipients. Of these notices, the majority were not easily classifiable beyond "text"-98 notices total, 16 self-reported OSPs, 82 Google notices. The text notices that were

136. Arguably the movie script notice could have been counted as a text notice; we elected to count it as a film-related notice because the sender was a motion picture company and the work was a derivative of a filmic work. See notice \#1432, http://chillingeffects.org/dmca512/notice.cgi?NoticeID=1432 (Sept. 21, 2004).

137. Notice \# 1882, http://chillingeffects.org/dmca512/notice.cgi?NoticelD=1882 (dated Apr. 26, 2005).

138. Notice \# 1139, http://chillingeffects.org/dmca512/notice.cgi?NoticelD=1139 (dated Feb. 25, 2004).

139. Notice \# 595, http://chillingeffects.org/dmca512/notice.cgi?NoticelD=595 (Feb. 27, 2003).

140. Notice \# 173, http://chillingeffects.org/dmca512/notice.cgi?NoticeID=173 (dated Feb. 19,2002 ); notice \# 151, http://chillingeffects.org/dmca512/notice.cgi?NoticelD=151 (dated Sept. 28, 2000); notice \# 234, http://chillingeffects.org/dmca512/notice.cgi?NoticeID=234 (dated Feb. 27, 2002) ("Presumably," because one of the notices listed only "such titles as. ..," rendering it unclear whether those titles were actually available for download or not. Notice \#234).

141. Notice \#156, unpublished, but mentioning DeCSS, and notice \# 1228 (notice available upon request from SANTA Clara COMPUTER \& HigH TECH. L.J.), in which the MPAA complained of downloads of two computer programs, "DVD Streamer" and "Flashdust," both of which permit streaming of DVDs.

142. Notice \# 1051 (notice available upon request from SANTA CLARA COMPUTER \& HiGH TECH. L.J.). This notice cited both $\S 512$ (c) and (d). We note that it is an open question whether Sharman qualifies as a $\$ 512$ (c) provider, a $\$ 512$ (d) provider, or neither. 
otherwise "unclassifiable" contained a mix of materials, or did not fit into the major categories of texts we had otherwise identified. For instance, we described the Diebold notices as unclassifiable text, because they included e-mails, internal correspondence and other materials. ${ }^{143}$ The Avatar/Star's Edge "lecture" materials were often included in "text," as were the Scientologist materials, a political site parodying the New York Times, ${ }^{144}$ and many others. Many "unclassifiable text" notices included text from websites. Of the "text" notices from which we could obtain more information, 21 related to systems or methods; 6 were obviously noncopyrightable data; 5 were e-mails posted by the recipient. Twenty-eight notices (or $16.8 \%$ ) were related to traditional literary texts-18 articles, 7 stories and 3 books. Of the "literary texts," we note that a number of these texts were redistributions of religious, spiritual or Scientology-like materials, including the Avatar notices. ${ }^{145}$ Four notices resulted from the author's reconsideration of the publication of the original article. 146

143. See, e.g., notice \# 911, http://chillingeffects.org/dmca512/notice.cgi?NoticelD=911; and notice \# 2372 (notice available upon request from SANTA CLARA COMPUTER \& HIGH TECH. L.J.).

144. Notice \# 1178, http://chillingeffects.org/dmca512/notice.cgi?NoticelD=1178 (dated Mar. 9, 2004).

145. See, e.g., notice \# 335, http://chillingeffects.org/dmca512/notice.cgi?NoticelD=335 (dated June 19, 2002) (Scientologists to Google requesting takedown from Google Groups of "confidential, unpublished, copyrighted works ... comprising levels known as 'NOTs"); \#352, http://chillingeffects.org/dmca512/notice.cgi?NoticelD $=352$ (July 18, 2002) (Church of Jesus Christ of Latter Day Saints requesting takedown of "a series of six textual missionary discussions" reprinted without authorization); notice \# 574 ,

http://chillingeffects.org/dmca512/notice.cgi?NoticelD $=574 \quad$ (Feb. 18, 2003) (requesting takedown from Google Groups of "The Vampire Bible"); notice \# 650,

http://chillingeffects.org/dmca512/notice.cgi?NoticelD=650 (Apr. 24, 2003) (requesting takedown from Google's cache of the "Ex-Premie" site the "complete texts to 14 complete songs and an entire book" owned by the "Premies," aka "Elan Vital"); notice \# 1226,

http://chillingeffects.org/dmca512/notice.cgi?NoticelD=1226 (Feb. 5, 2004) (Evangelical Christian tract publisher requests takedown of parody); notice \# 1340,

http://chillingeffects.org/dmca512/notice.cgi?NoticelD $=1340 \quad$ (July 21, 2004) (Religious copyright owner requests takedown of material from critic's website). See also Theresa A. Lyons, Scientology or Censorship: You Decide. An Examination of the Church of Scientology, Its Recent Battles with Individual Internet Users and Service Providers, the Digital Millennium Copyright Act, and the Implications for Free Speech on the Web, 2 RUTGERS J. OF L. \& RELIGION 1 (2000) (discussing the background of the Scientologist disputes, and expressing concern that the DMCA will contribute to suppression of speech).

146. See, e.g., notice \# 273, http://chillingeffects.org/dmca512/notice.cgi?NoticelD=273 (dated Mar. 15, 2002); notice \# 1725,

http://chillingeffects.org/dmca512/notice.cgi?NoticeID=1725 (dated Feb. 16, 2005); notice \# 1907, http://chillingeffects.org/dmca512/notice.cgi?NoticelD=1907 (dated May 5, 2005) (not 
Of the 37 photo-related $\S 512$ (c) notices, a small number (three) were personal photos that the subject wanted removed. Two were parents requesting takedown of photos of children, 147 and one was an individual requesting takedown of photos of himself from a critical website. ${ }^{148}$ Fifteen of the 37 photo-related $\S 512(\mathrm{c})$ notices were sent to OSPs other than Google; these included at least four identifiably pornography-related claims; seven from Leslie Kelly, plaintiff in Kelly v. Arriba; ${ }^{149}$ three personal photographs; and a celebrity photograph, possibly altered into pornography. Of the 22 photorelated $\S 512(\mathrm{c})$ notices sent to Google, at least seven were pornography-related claims, including some from Perfect10. The remainder included a variety of photographs, including professional, artistic and non-commercial photographs. We note that the allegedly infringing use of the works often seemed to incorporate the work into a larger work, such as an illustration of an article or a commentary. Further study on the derivative, transformative or substitutive use of photographic works, and the mix of personal, nonprofit or commercial uses, would be appropriate.

Of the $70 \S 512$ (c) notices that were sent regarding software or computer games, 53 notices $(76 \%)$ obviously or likely targeted anticircumvention devices rather than direct copyright infringement of the code. We discuss issues related to anticircumvention notices further below. Of the other claims included within the notices, nine related to distributions of the program or game, five to apparent

published for other reasons). Two notices are $\S 512$ (c) and two notices cite both $\S 512(\mathrm{c})$ and (d).).

147. See, e.g., notice \# 2189, http://chillingeffects.org/dmca512/notice.cgi?NoticelD=2189 (dated July 28, 2005) ; notice \# 2199,

http://chillingeffects.org/dmca512/notice.cgi?NoticeID=2199 (dated July 29, 2005).

148. See notice \# 954, http://chillingeffects.org/dmca512/notice.cgi?NoticeID=954 (dated Nov. 11, 2003). It is sometimes difficult to understand the history of the notices. In this instance, the "critical" site used the photos to illustrate the blogger's critique of the individual, such as the individual's habit of driving expensive cars. Depending on the underlying factual circumstances, this kind of criticism might be construed as performing a useful service, or as a form of harassment or defamation. However, the $\S 512$ process creates a simple action for enforcing copyrights only, not torts. Any balancing of speech and privacy rights that might take place in a judicial action between the speaker and the complainant are elided by this substitution of actions on the part of the complainant. But see Michael L. Rustad \& Thomas H. Koenig, Rebooting Cybertort Law, 80 WASH. L. REV. 335 (2005) for a proposal that a $\$ 512$ notice-and-takedown regime be implemented for speech-related torts, replacing Section 230. While Rustad and Koenig acknowledge that $\S 512$ has had speech-chilling effects, they suggest that a tort-version could have sufficient procedural protections to avoid the problem.

149. Kelly v. Arriba, 280 F.3d 934 (9th Cir. 2002). Leslie Kelly has filed multiple takedown notices against sites that have used his photographs. See Chilling Effects at http://www.chillingeffects.org. 
resales and three to distributions of the source code. We have surprisingly few notices related to so-called "warez" sites-only $12.9 \%$ (nine notices) related to distributions of software, games or code. This may be an artifact of our data, which has few notices to small webhosts; perhaps our review of the notices from The Planet, which provides webhosting, will show a different picture.

\section{512(d) (Information Location Tools) Notices}

The $\S 512(\mathrm{~d})$ set showed roughly similar composition of subject matter to the $\S 512(\mathrm{c})$ notices, with significantly more takedown requests complaining of links to text than any other kind of subject matter-329 of 521 notices ${ }^{150}(63.1 \%)$ asked for removal of links to text materials-unsurprisingly, mostly web-related content, as we discuss below.

Movie industry companies sent only 12 of the $\S 512$ (d) notices, and music industry companies sent only two. The software and games industries sent $56 \S 512$ (d) notices requesting removal of links. Of the 56 total $\S 512$ (d) notices relating to software or computer games, $46 \%$ (26 notices) presented anticircumvention claims, and 54\% (30 notices) presented only non-anticircumvention claims. Compared with $\S 512(\mathrm{c})$, more $\S 512(\mathrm{~d})$ notices requested the removal of links offering downloads of works- $48.3 \%$ of the software and game $\S$ 512(d) notices (28 notices). ${ }^{151}$ Some of the notices presented multiple claims, including complaints of reverse engineering, derivative works or resales of software.

Notices related to photographs comprised $13 \%$ (68 notices) of the $\S 512$ (d) notices, with other graphics at $4.6 \%$ (24 notices). As with the $\S 512$ (c) notices, some of the $\S 512$ (d) notices (eight) described what appeared to be personal photographs that the subject wanted delinked; in only two of these eight notices was it clear that the sender understood that ownership of the copyright likely belongs to the photographer rather than to the subject. ${ }^{152}$ And again, as with the

150. Note that, if one takes each category of content (text, movies, music, etc.) separately, one will find that the percentages do not add up to $100 \%$ because some notices included multiple claims relating to different kinds of subject matter.

151. In most of these notices, the presence of the downloadable files could not be verified, presumably because the files or posting had been taken down.

152. Notice \# 1763, http://chillingeffects.org/dmca512/notice.cgi?NoticelD=1763 (dated Mar. 21, 2005), states this more clearly, and possibly stated in notice \# 1179, http://chillingeffects.org/dmca512/notice.cgi?NoticeID $=1179$ (dated Mar. 15, 2004). The other notices included only the formal language of the DMCA, or other information not relating to the copyright ownership issues. See, e.g., notice \#s 1092, 1207, 1233, 1234, 1235, and 1242 (available by visiting http://chillingeffects.org/dmca512/notice.cgi?NoticeID= followed by the 


\section{$\S 512$ (c) photograph notices, a few of these eight $\S 512$ (d) photograph} notices presented obvious personal privacy issues. For example, one complainant explicitly stated that "[t]he image on the above link has my photo. I do not want people to search my name and see my photo. I feel uncomfortable."153 The general composition of $\S 512(\mathrm{~d})$ photographic notices was largely similar to the $\S 512$ (c) set: a mix of notices citing professional (including pornographic) works and amateur works on a wide variety of topics.

Looking more closely at the $329 \S 512$ (d) notices complaining of links to text-based material, $50.5 \%$ (166) of the 329 notices cited web copy of some sort-some portion of a website, but not the entire website. ${ }^{154}$ Thirty-eight $(11.6 \%) \S 512$ (d) "text" notices complained of plain product descriptions. Reviews of individual notices show that in a number of additional notices the complaint related more broadly to descriptions of services or features-effectively, ad or brochure copy. At least half a dozen notices claimed copyright over metatags. ${ }^{155}$ Over and beyond the numerous notices requesting takedown of text-related webcopy, an additional 53 notices alleged copying of an entire website, and requested removal of links to the entire site.

notice \#). The DMCA only states that the complainant must attest that they are the copyright owner or an authorized representative. 17 U.S.C. $\$ 512$ (c).

153. Notice \# 1233, http://chillingeffects.org/dmca512/notice.cgi?NoticeID=1233 (dated Apr. 16, 2004).

154. In addition to these text-based notices that alleged copying of a portion of a website, an additional 53 claimed copying of an entire website. Because an entire website might include a variety of media or programming, we did not count those 53 notices in "text," but elected to count them separately. The distinction between an accusation of copying an entire website and copying some other lesser portion of a website is meaningful but difficult to ascertain from just a complaint-and difficult to determine even with significant review of the websites. Certainly, copying an entire site without permission is highly suggestive of, if not presumptively, infringement; whereas, copying lesser portions of a site might well be protected if those portions are factual in nature, de minimis, or used transformatively, for instance. These distinctions were made to the best of our ability, but it was difficult to determine with many of these notices how much of the website was alleged to have been copied. Complainant often used language suggestive of significant copying, but reviews of the sites rarely tumed up exact mirror images. For our purposes, we counted any notice that alleged "mirroring," the "whole website," or similar terminology as a complaint about the entire website, even though we recognized that reliance on the complainant's description could result in over- or under-inclusiveness on this metric. We counted all other web-text related complaints as web copy-which could vary from just a tiny amount of text, to a large portion of the website, or an entire section of a website.

155. See, e.g., notice \# 2225 (notice available upon request from SANTA CLARA COMPUTER \& HIGH TECH. L.J.); notice \# 2032,

http://chillingeffects.org/dmca512/notice.cgi?NoticeID=2032 (dated June 9, 2005). Metatags are not copyrightable, although they may include trademarks. Many notices used more generic language than "metatags," claiming keyword tagging or other related concepts. Most such complaints also included complaints about infringement of other website content, such as layout, CSS, HTML, or content. 
This area begs study, as there is little caselaw delineating what aspects of a website are copyrightable expression and what are functional, ideas, or otherwise not protectable.

Of the $329 \S 512(\mathrm{~d})$ notices targeting text materials, $70(21.2 \%)$ were based on literary properties of various sorts, including four notices citing books and 66 citing "articles" or "stories" (including blog postings). ${ }^{156}$ The infringement claims here seemed strong. Dissemination of short text articles in their entirety seems likely to be infringing and not a fair use, should such a complaint be litigated. ${ }^{157}$ Likewise, disseminations of entire short stories or poems seem likely to constitute infringement.

As with notices targeting photographs, some of the $\S 512(\mathrm{~d})$ notices targeting text described various personal privacy or dignity concerns. Seven notices related to private e-mails posted publicly. ${ }^{158}$ At least 18 notices expressed a wish to de-index content because of embarrassment over the text. ${ }^{159}$ A few complainants expressed unhappiness over the circumstances of the current publication, rather than the publication per se. ${ }^{160}$

\section{Section 512(a) (ISP) Notices}

We stress that our set of $\S 512(a)$ notices is statistically unreliable. There are only 68 such notices, and all were selfsubmitted. Nevertheless, we include this section to complete the

156. See, e.g., notice \# 641, http://chillingeffects.org/dmca512/notice.cgi?NoticeID=641 (dated Apr. 21, 2003) (short story "Pornucopia" posted to Google Groups).

157. 17 U.S.C. $\$ 107$. The primary variation would be in the first factor, the "purpose and character of the use." If the full-text of an article is posted on a website with no additional commentary or other transformative features, then the effect on the market for the original article is likely to hinge on the circumstances surrounding the website, such as whether it is accessible or publicized to the world or just a small set of, for instance, educational users or organizational members.

158. See, e.g., notice \#1220, http://chillingeffects.org/dmca512/notice.cgi?NoticelD=1220 (dated Mar. 26, 2004) (requesting takedown of a transcript of a private chat).

159. See, e.g. notice \#892, http://chillingeffects.org/dmca512/notice.cgi?NoticelD=892 (dated Oct. 4, 2003); notice \# 312, http://chillingeffects.org/dmca512/notice.cgi?NoticeID=312 (dated May 7, 2002) (one of a series of related notices). There were at least twenty notices making such claims in the dataset; sixteen were $\S 512$ (d) notices; two were $\S 512$ (c); and two were both $\S 512$ (c) and (d). See supra note 145 and accompanying text.

160. See, e.g., notice \# 611, http://chillingeffects.org/dmca512/notice.cgi?NoticelD=611 (dated Mar. 20, 2003) (the author of an article was unhappy that a Holocaust denier was republishing the author's work); \#671,

http://chillingeffects.org/dmca512/notice.cgi?NoticeID=671 (dated May 12, 2002) (the author of a poem requested takedown of a notice that reposted the poem in a way that the author felt "defames myself and my reputation"; the e-mail "included derogatory comments about the author."). 
picture of subject matter sent under the various sections in our data set.

As previously discussed, the movie industry sent the majority of these notices: 45 notices (66\%). These were most typically form notices alleging peer-to-peer file sharing of commercially copyrighted films from major studios, ${ }^{161}$ although a few were apparently pornography. ${ }^{162}$ Nine notices made software-related claims, typically sent by BayTSP (a DMCA enforcement company) or the Business Software Association (BSA). ${ }^{163}$ Six notices were computer gamerelated, all sent by either the Interactive Digital Software Association (IDSA) or the Entertainment Software Association (ESA). ${ }^{164}$ Only four notices were from the music industry. 165 The remaining notices were unclassifiable or multimedia, including one audiorecording of a book. ${ }^{166}$

\section{F. Enforceability, Substantive Legal Flaws and Process- Related Concerns}

Perhaps most striking, we found that at least a third of notices contain at least one of the major categories of flaws we evaluated. These categories pose significant questions about the claim's enforceability in a court of law and/or invite serious concerns about the fairness of the process for targets. They are:

- substantive legal questions related to the underlying copyright claim; and

- significant technical noncompliance that renders the notice unusable according to the statute.

This figure does not include other questionable uses of the $\S 512$ takedown process, such as sending notices where $\S 512(\mathrm{a})$ would apply, complaining of anticircumvention information, ${ }^{167}$ or sending

161. See, e.g., notice \# 1349, http://chillingeffects.org/dmca512/notice.cgi?NoticeID=1349 (dated Aug. 2, 2004) (Cox forwarding to their customer a BayTSP notice on behalf of Paramount, alleging sharing of "Star Trek Nemesis.").

162. See, e.g., notice \# 857, http://chillingeffects.org/dmca512/notice.cgi?NoticelD=857 (dated Sept. 8, 2003).

163. See, e.g., notice \# 713, http://chillingeffects.org/dmca512/notice.cgi?NoticelD=713 (dated July 17, 2003).

164. See, e.g., notice \# 1366, http://chillingeffects.org/dmca512/notice.cgi?NoticeID=1366 (dated Apr. 28, 2004).

165. See, e.g., notice \# 1489, http://chillingeffects.org/dmca512/notice.cgi?NoticeID=1489 (dated Nov. 15, 2004).

166. Hany Potter, of course. Notice \# 532, http://chillingeffects.org/dmca512/notice.cgi?NoticelD=532 (dated Jan. 23, 2003).

167. See supra note 98 and infra Sec VI.F.6. for discussion of this issue. 
notices when complicated questions of international law are relevant. We also did not count some categories of notices that are arguably fair use or otherwise defensible, as described in Section $V$, Methodology, above. In this section, we describe the notices that comprise the "flawed one-third," as well as some other perhapsproblematic notices that we discovered but did not include in the count.

\section{Issues with Underlying Copyright Claim.}

We first examined significant questions related to the underlying copyright claim, including fair use defenses, other substantive defenses, very thin copyright, or non-copyrightable subject matter. Fig. 8. Surprisingly, $31 \%$ of $\S 512$ (c) and (d) notices present claims that fall into this category. ${ }^{168}$ As a rule of thumb, we tried to capture notices where a genuine dispute related to copyright infringement or defenses would clearly arise. Examples range from the clearly problematic-for example, recipes, prices and metatag information, which are unlikely to be covered by copyright--to instances of very thin copyright claims, such as very short product descriptions. We also included notices where the target was likely to have a fair use defense. A much smaller number of notices in this category were counted due to other substantive concerns, such as questions regarding the ownership of the copyright in question: for example, a small number of notices appear to be sent not by the copyright holder or a representative, but by a party with some other interest in the material, such as the subject of a photograph. Among § 512(c)-(d) notices sent to Google, at least one type of substantive, subject-matter flaw was apparent in 209 notices, or $29 \%$ of the Google set. Among the self-reported $\S 512$ (c)-(d) notices, $43(59 \%)$ of the self-reported notices had at least one substantive flaw.

168. Notices often present multiple claims, describing multiple works, multiple alleged infringements, and often multiple target sites. Such notices might present a mix of problematic and non-problematic claims. For our analysis, we counted notices with at least one problematic claim. Any notice is only counted once-i.e, we do not count a notice again if it has multiple problematic claims. 
Notices by Type of Flaw (Google and Non-Google)

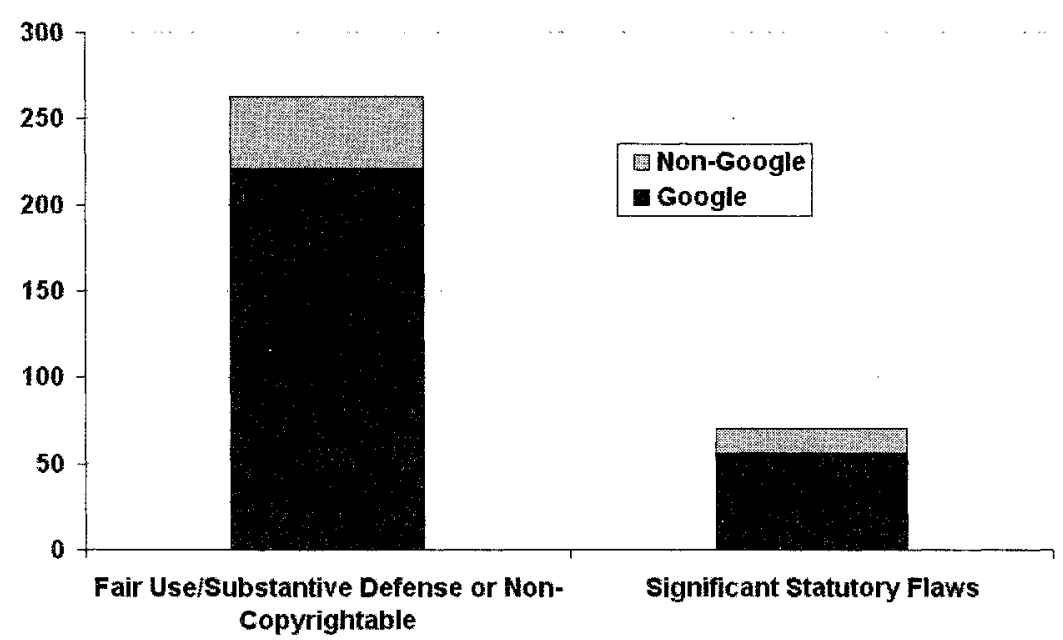

Fig. 8. Significantly flawed \$ 512(c)-(d) notices.

One issue present in the $\S 512(\mathrm{c})$ and $\S 512(\mathrm{~d})$ notice datasets is the problem of noncopyrightable subject matter. A total of 37 notices include claims for noncopyrightable subject matter, such as recipes, ${ }^{169}$ pricing information, ${ }^{170}$ forms ${ }^{171}$ and methods. ${ }^{172}$ The American Poolplayers Association sent takedown notices for posting

169. See, e.g., notice \# 1327, http://chillingeffects.org/dmca512/notice.cgi?NoticeID=1327 (dated June 24,2004 ). While the text and photos surrounding a recipe can be copyrighted, the instructions and ingredients of the recipe cannot. See 37 CFR $\S 202.1$ (a) (listings of ingredients are not copyrightable) and 17 U.S.C. $\$ 102$ (b) (procedures and processes are not copyrightable); see also Publ'ns Int'l, Ltd. v. Meredith Corp., 88 F.3d 473 (7th Cir. 1996) (no copyright for recipes from a compilation cookbook). But see Barbour v. Head, 178 F. Supp. $2 \mathrm{~d} 758$ (S.D. Tex. 2001) (recipes included significant commentary and creative description which precluded summary judgment as to noncopyrightability of recipes).

170. See, e.g., notice \# 960, http://chillingeffects.org/dmca512/notice.cgi?NoticeID=960 (dated Nov. 17, 2003). Assignment of prices for sale of an item are likely not copyrightable, as they are basic factual information. However, pricing information is not per se uncopyrightable. Estimates that involve calculations, formulas and algorithms are more creative. For example, determination of average prices for a consumer pricing guidebook involves creative calculations, and may produce copyrightable information. See, e.g., CDN Inc. v. Kapes, 197 F.3d 1256 (9th Cir. 1999).

171. See, e.g., notice \# 2085, http://chillingeffects.org/dmca512/notice.cgi?NoticelD=2085 (dated June 23, 2005). Forms are not subject to copyright. 37 CFR $\$ 202.1$; Baker v. Selden, 101 U.S. $99(1880)$.

172. See, e.g., notice \# 993, http://chillingeffects.org/dmca512/notice.cgi?NoticelD=993 (dated Dec. 3, 2003). "In no case does copyright protection ... extend to any idea, procedure, process, system, method of operation, concept, principle, or discovery. ..." 17 U.S.C. § 102(b). 
its handicap formula. 173 (Formulas are specifically excepted from copyright by 17 U.S.C. $\S 102(b) .{ }^{174}$ ) Release of the handicap formula may present other claims, such as trade secrecy, but the notices were standard $\S 512$ takedown notices, and made no additional allegations. Further, the notices we reviewed did not directly copy the formula from the manual, but instead described the formula, even paraphrasing and adding commentary. Recipes are likewise exempted from copyright as formulas or methods of operation. ${ }^{175}$ Although substantial literary expression in the form of surrounding text and photographs may be copyrightable, the base recipe is not. Yet several notices in the database claimed copyrights over recipes, and demanded takedown of copies. ${ }^{176}$ Pricing information is also largely factual, yet complainants targeted the release of pricing and sales information. ${ }^{177}$

Questions of copyrightability were also raised by a variety of takedown notices relating to factual material in databases, ${ }^{178}$ product descriptions and photographs, and forms and templates. For instance, Yahoo! claimed a copyright on blog templates that emulate the Yahoo! look-and-feel. ${ }^{179}$ These templates were developed by blog users for personal use and submitted by their user-developers to Google's Blogger user template space. The copyrightable expression in Yahoo!'s template and layout is likely to be thin indeed; it seems a genuine dispute over infringement would arise. 180 Many of these types of notices fall into a continuum of complaints that relate to websites being spidered and used for other purposes. The targets may be using the content for a variety of purposes: indexing product

173. Id. Most of the other notices related to reposts of the original post, along with discussion of the putative intellectual property rights. See, e.g., notice \# 1197 , http://chillingeffects.org/dmca512/notice.cgi?NoticeID=1197 (dated Feb. 18, 2004).

174. "In no case does copyright protection for an original work of authorship extend to any idea, procedure, process, system, method of operation, concept, principle, or discovery, regardless of the form in which it is described, explained, illustrated, or embodied in such work." 17 U.S.C. $\S 102(\mathrm{~b})$.

175. See 17 U.S.C. $\$ 102(b)$ and 37 CFR $\S 201.1$.

176. See, e.g., notice \# 2207, http://chillingeffects.org/dmca512/notice.cgi?NoticeID=2207 (dated July 25, 2005).

177. See, e.g., notice \# 952, http://chillingeffects.org/dmca512/notice.cgi?NoticelD=952 (dated Nov. 14, 2003) (from Best Buy).

178. See, e.g., notice \# 1260 , http://chillingeffects.org/dmca512/notice.cgi?NoticeID $=1260$ (dated May 4, 2004) (real estate database).

179. See notice \# 2085, http://chillingeffects.org/dmca512/notice.cgi?NoticeID=2085 (June 23, 2005).

180. Yahoo! also alleged trademark claims. 
information, as in Google's Froogle service; ${ }^{181}$ generating search engine hits for "link farms"; referencing competitor's products; or emulating a competitor's website. While some such claims may be very sympathetic, such as complaints about URLs being used in a socalled link farm, they skirt the boundary of copyright protection. 182 But the $\S 512$ process admits no such gray areas; takedown removes any work alleged to infringe, regardless of the nature of the infringement.

Product information constitutes another problematic area for copyrightability. In complaints about product information, the copyrighted work may consist of a factual description of a product, accompanied by a very basic, "factual" photograph of the product. While there is no question that such product information in advertising can rise to high levels of artistry, ${ }^{183}$ few of the product information notices we reviewed demonstrated much originality. Rather, the product descriptions were often short and descriptive. Similarly, product photographs did not display any particular attention to lighting, background, angle, etc.; rather, they simply showed the described object. ${ }^{184}$ While the level of originality required for copyright protection is a mere quantum, at the least, it is likely to be difficult to distinguish between noncopyrightable facts and the copyrightable expression in short, factual, textual product descriptions and representative, non-artistic product photos. ${ }^{185}$ As such, we think

181. See, e.g., notice \# 1265 , http://chillingeffects.org/dmca512/notice.cgi?NoticeID=1265 (Apr. 23, 2004).

182. The merger doctrine holds that where the noncopyrightable idea and the copyrightable expression are inseparably merged, no copyright may be accorded to the work. See Morrissey v. Proctor \& Gamble Co., 379 F.2d 675 (1st Cir. 1967) (merger doctrine prohibits copyright of lottery instructions); Baker v. Selden, 101 U.S. 99 (1880) (no copyright of an accounting form).

183. See the annual Clio advertising awards, http://www.clioawards.com (last visited Apr. 25, 2006).

184. Product photos indeed provide thin copyrightability, and a fine line for assessing copyrightable expression and infringement. Ets-Hokin v. Skyy Spirits Inc., 323 F.3d 763 (9th Cir. 2003). Cf. Schiffer Publ'g, Ltd. v. Chronicle Books, LLC, No. Civ.A. 03-4962, 2004 WL $2583817,{ }^{*} 10$ (E.D. Pa. Nov. 12, 2004) (examining photos of quilting patterns for creative choices, including "the highlighting of certain colors and the muting of others; an extra emphasis on a pattern's texture; and the heightened visibility of stitching in certain of the quilt photographs.... Even though Plaintiffs' copyrights in their photographs may be 'thin,' they are robust enough to offer protection here.").

185. We observed some related complaints regarding press releases describing services offered by companies. Press releases-especially creative ones-are probably generally less factual and more imaginative than mere product descriptions. However, claims of infringement of language in press releases, or compilations of listings, were sometimes confusingly intertwined with claims about titles, trademarks, meta-tags, and the like. The District Court in the District of Columbia just disposed of one such case, finding that the plaintiff had significant 
that such notices require review before takedown, and counted them as problematic based on the very thin copyright claim, and the strong fair use claim that use of such thinly-copyrighted works often presented. ${ }^{186}$ These notices probably represent our least conservative coding practice; yet, we were careful to count only those where the copyright was thin, indeed, and expect that we undercounted them due to lack of detailed information in many notices. ${ }^{187}$

Similar issues plague the large number of notices claiming infringement of website "layout" or design. Following our policy of conservatively coding notices for problems, we elected not to include this category of notices in our count of substantively flawed notices, because they present too many analytic challenges. Each such claim should be separately analyzed to determine its validity. In instances where an entire site is 'mirrored' or copied, it is certainly likely that copyright infringement is occurring. However, some cursory examination of these claims reveals that some claims are not so strong, and may in fact be considerably weaker. Our brief analysis suggests that at least in some instances, the underlying copyright is again, thin, resting on, for instance, the hierarchical scheme of laying out pages of content; but we do not have enough information about many of these notices to place them in the "flawed" category. $188 \mathrm{We}$ do note that if a large proportion of the "website layout" claims rest

problems stating a claim. Terry Newborn v. Yahoo!, Inc., 391 F. Supp. $2 d 181$ (D.D.C. 2005) (dismissing plaintiffs' copyright, DMCA, and trademark claims for failure to state a claim).

186. For instance, Google's Froogle, which indexes product information, has received notices requesting material be de-listed. See, e.g., notice \# 1265,

http://chillingeffects.org/dmca512/notice.cgi?NoticeID=1265 (dated Apr. 23, 2004). While Google complies with such requests even absent DMCA takedowns, indexing such material is likely a fair use. All the factors from Kelly v. Arriba would apply, but in addition, the copyright on the underlying work is thinner for product photos than for artistic photos, and there is little or no market for the original product photos and descriptions. Kelly v. Arriba, 280 F.3d 934 (9th Cir. 2002).

187. See, e.g., notices \# 19242021 and 2027 (available by visiting

http://chillingeffects.org/dmca512/notice.cgi?NoticeID= followed by the notice \#). Here we examine only the level of copyrightable content in the product descriptions and photos included in the Chilling Effects database. However, these product description notices may raise other issues as well. These notices are often competitor-related notices, where one reseller describes a product and/or takes a photo of the product, and a second reseller uses that product information in their own marketing materials. The original reseller's product information may also be based on product information from the manufacturer. See, e.g., notice \# 1473,

http://chillingeffects.org/dmca512/notice.cgi?NoticeID=1473 (dated Oct. 9, 2004).

188. It is difficult to assess a claim which consists entirely of several categories of thinly copyrightable content, such as website layout; meta-tags; and database scrapings of product descriptions. The strength of the copyright claim would be increased by the use of these elements in aggregation, but unfair competition might be a more accurate description of the grievance than "copyright infringement." 
on thin (or vanishing) copyright, this would be of particular concern, because many of these notices appear to be related to competitors seeking to de-list their competitors in the Google search engine.

\section{Other Defenses}

A small number of notices presented various other defenses. For instance, a small number of claims present obvious questions of ownership. In at least seven notices, for instance, the apparent subject, or parent of the subject, of a photograph wrote to request that the photograph be removed from the Internet. While the $\S 512$ formalities were observed - the sender attests that they are the copyright owner or a representative - on reading the notice, it seems likely that the sender has misapprehended copyright law, and does not understand that the photographer is the likely copyright owner.

Two notices presented a different ownership question: software designers claimed that their client had failed to pay for a website design, and that they therefore owned the copyright. ${ }^{189}$ To even begin to evaluate the validity of such a claim would require analysis of the contract between the software designers and their clients, a task clearly unsuited for search engines and webhosts. ${ }^{190}$ These ownership-related issues between Web contractors and their clients also included a complaint that a former client had altered the website design by removing information about the website designer-the legality of which was centrally dependent on resolution of the ownership question. ${ }^{191}$ Another ownership-related dispute relied on a

189. See notice \#1256, http://chillingeffects.org/dmca512/notice.cgi?NoticeID=1256 (dated May 2, 2004); notice \# 477, http://chillingeffects.org/dmca512/notice.cgi?NoticeID=477 (dated Nov. 12, 2002).

190. Indeed, in a case with a similar dispute between a website designer and its former employer, the court determined that the work was likely a work-for-hire, and the contract did not condition transfer of ownership on full payment. IXL Inc. v. AdOutlet.com, Inc., No. 01 C 0763, 2001 WL 315219 (N.D. Ill.; Mar. 29, 2001). Disputes between parties to a contract pose questions that no OSP is in a position to evaluate, even if there were an incentive for the OSP to do so. The process can become quickly complex; both of the parties have recourse to the quick and easy extrajudicial proceedings of the $\S 512$ takedown process. In Relate $L L C \nu$. Jones, another dispute over ownership, one party had to be enjoined from sending takedown notices to the other party's ISP. Both parties had apparently sent notices. Relate LLC v. Jones, No. 050176-CV-W-FJG, 2005 WL 1936337 (W.D. Mo. Aug. 8, 2005).

191. See notice \# 1256, http://chillingeffects.org/dmca512/notice.cgi?NoticeID=1256 (dated May 2, 2004). The sender, a website design company, complained that the target had not paid for the website and had altered it without permission. The senders claimed they did not "release the copyright from the design portion of these websites." Aside from the ownership dispute, the underlying copyright claim is itself quite complex, and would require separating the design elements from the text, and then assessing whether removal of the designer's information constituted a derivative work. Section 1202 of the DMCA, removal of copyright management 
client's complaint that a former web-designer had maintained a copy of the website, which was achieving higher search rankings than the client's. ${ }^{192}$ Yet another notice claimed ownership over a work in the public domain. ${ }^{193}$ One notice was sent as part of an ongoing dispute among at least three different parties, all of whom claim ownership over a single work known as the "Footprints" poem. ${ }^{194}$ These vexing issues are also reflected in the limited available caselaw. In Relate $v$. Jones, an ownership dispute that apparently involved multiple crossnotices between the parties. One party ultimately obtained an injunction barring the other from filing DMCA notices with his ISP. 195 Ownership of a copyright is handled, in the $\S 512$ process, with a simple attestation of ownership. Yet these examples suggest that ownership of copyright-the threshold question before any claim can be made-is readily misunderstood.

One sender sent two claims, seeking to remove blogs that linked to allegedly copyright infringing materials-tertiary linking. 196 Linking to material merely alleged to infringe 17 USC $\S 106$ is unlikely to be deemed even contributory infringement. 197 Responsibility for hosting or indexing a site which links to a site that

information may also constitute a separate claim, but (properly) no such claim was stated in the notice. 17 U.S.C. $\S 1202$.

192. See notice \# 373, http://chillingeffects.org/dmca512/notice.cgi?NoticeID=373 (dated Aug. 2, 2002).

193. See notice $\# 595$, http://chillingeffects.org/dmca512/notice.cgi?NoticelD=595 (dated Feb. 27, 2003). Such errors are likely when copyright holders attempt to automate the process of locating copyright infringement, by sending notices in bulk in reliance on automatic searches of keywords or filenames. See Lauren McBrayer, The DirecTV Cases: Applying Anti-SLAPP Laws to Copyright Protection Cease-and-Desist Letters, 20 BERKELEY TECH. L.J. 603 (2005) (describing the bot processes used to automatically locating potentially infringing files).

194. Notice \# 1531, http://chillingeffects.org/dmca512/notice.cgi?NoticelD=1531 (dated Nov. 12, 2004). The work is "Footprints," a religious poem that has been frequently printed and widely distributed with various attributions. The notice by itself puts forth a sympathetic case. A recipient OSP or target would have to research the facts and history of the notice to realize that authorship of the poem is disputed among multiple parties, and then determine how to respond to the notice.

195. Relate LLC v. Jones, 2005 WL 1936337. See also IXL Inc. v. AdOutlet.com, Inc., No. 01 C 0763, 2001 WL 315219 (N.D. Ill., Mar. 29, 2001).

196. Notice \# 2038, http://chillingeffects.org/dmca512/notice.cgi?NoticelD=2038 (dated June 13,2005 ); notice \#1944, http://chillingeffects.org/dmca512/notice.cgi?NoticelD=1944 (dated May 9,2005 ). We note that in these notices, the complainant was not a US national, and may not have been familiar with the nuances of US copyright law on liability for linking. See also notice \#548 (available upon request from the author) (Scientologists complain to a website for mirroring Operation Clambake's site, but all the content is actually on Operation Clambake).

197. Tertiary linking was considered a form of "distribution" of a $\$ 1201$ circumvention tool in Corley, but that is distinct from the $\S 106$ exclusive right of distribution. Univeral City Studios, Inc. v. Corley, 273 F.3d 429 (2d Cir. 2001). 
contains allegedly copyright infringing material seems clearly beyond the scope of responsibility of $\S 512$ OSPs.

\section{Statutory Flaws}

Significant statutory flaws plagued one out of every eleven notices. Fig. 8 , above. By "significant" statutory flaws, we mean one of the four flaws that render a notice invalid according to the terms of the statute: 198 failure to identify the allegedly-infringing work; failure to identify the allegedly-infringed work; failure to provide a way to locate the allegedly-infringing work; or failure to provide contact information for the complainant. Other statutory flaws-the good faith and penalty of perjury statements, and the signature-do not exempt an OSP from responding to the notice, and notices exhibiting these flaws are not included in this figure. Takedowns based on notices with the significant flaws present significant burdens to the recipient OSPs and questions of fairness to the target. A complaint failing to identify the infringed or infringing works fails to make any genuine showing of a controversy, however limited the review of the merits of the controversy may be. Complaints that do not identify the location of the allegedly infringing work may result in over- or underinclusive takedowns. The complainant contact information is important because alleged infringers have no way to respond with a counternotice if the OSP cannot reach the complainant.

\section{Section 512(a) Notices}

The non-Google data also show a high incidence of notices$48 \%$, nearly half-where OSPs are actually acting merely as conduits, providing transmission and routing. At their most complete, the notices in the Chilling Effects database include a copy of the original complaint, accompanied by a warning or threat from the OSP to the user. ${ }^{199}$ The original complaint might include an "infringement

198. Section 512(c)(3)(A) sets forth the statutory requirements. Section $512(\mathrm{c})(3)(B)(i i)$ specifies which clauses constitute "substantial compliance" and require some action by the OSP.

199. A number of notices were forwarded by OSPs without the original complaint. If no additional information relating the complaint to copyright or particular copyright claims was included, these notices were not included in the set of $\S 512$ (a) notices. If a so-called "infringement report" was included without the original complaint, then we analyzed the notice based on the OSP and alleged infringer content, and extrapolated the industry and corporate or individual status based on the "infringement report". For instance, where a report listed an obvious movie title or described the infringed work as a movie, we described the sender as movie industry. We made one additional extrapolation to describe the complainant as "corporate." In no instances did individual producers or directors send cease-and-desist notices; in all instances the complainant was either the primary rights holder (the production company) 
activity report" citing an IP address, a network protocol, and a file alleged to have been distributed. ${ }^{200}$ Most complained-of material appeared to reside on users' machines, made available via broadband Internet access through a peer-to-peer network. ${ }^{201}$ As noted supra, transmission service falls under $\S 512(a)$, under which OSPs receive a safe harbor without taking any material "down." 202 In fact, as the material resides on user computers rather than OSP servers, there is no way for the OSP to take material down, at all. ${ }^{203}$ We suspect that the advent of P2P has pushed some of $\S 512$ 's intended beneficiaries-content providers-into sending notices where

or a DMCA enforcement agency. The infringement reports are quite standard and obviously generated by particular DMCA enforcement agencies, but we chose to not extrapolate their identities. The only notice that was not clearly identifiable as to industry was one for "Spiderman" (sic). We ultimately determined that referred to a set of game "cheats" for the Spiderman video game, after examining file types, and finding a discussion about that very notice in a chat forum. All other notices clearly fell into particular content industries.

200. See, e.g., notice \#1347, http://chillingeffects.org/dmca512/notice.cgi?NoticeID=1347 (dated July 31,2004 ). One exception is the small number of notices sent to upstream Internet access providers for webhosts. See, e.g., notice \# 500,

http://chillingeffects.org/dmca512/notice.cgi?NoticeID $=500$ (dated Dec. 3, 2002) (Dow Chemical's notice to Verio, upstream service provider for a political satire group, the Yes Men).

201. Of the $\S 512$ (a) notices in our data set, almost all are OSP notices to consumers, which the consumer submitted to Chilling Effects. These consumer-submitted notices varied in what communications they included. Some included only the notice from the OSP to the consumer; some included only the notice from the complainant to the OSP; and some included both communications from the complainant to the OSP, and from the OSP to the consumer. Some submissions included additional correspondence or notes. Of the notices where a consumer submitted only the OSP notice to the consumer, the basis of the original complaint was not always apparent. For instance, the OSP might have cited only a "terms of service" violation, without specifying copyright infringement or the DMCA. In examining the $\S 512$ (a) data set, we only counted notices which included the original complaint, or where the OSP had included sufficient information to tie the OSP notice to a copyright infringement claim. We included, therefore, notices that stated that the complaint was for copyright infringement, cited $\S 512$ or "DMCA takedown notice," or where the OSP cited a content-owner and identifiable copyrighted content.

202. One student commentator suggests that courts have had difficulty understanding what services qualify as a $\S 512$ (a) OSP. Sven Eric Skillrud, An Umbrella or a Canopy?: Why the 17 U.S.C. Section 512(a) Safe Harbor Should Be Read Broadly, 9 MARQ. INTELL. PROP. L. Rev. 91 (Winter 2005).

203. See, e.g., In re Charter Commc'ns, Inc., 393 F.3d 771, 776 (8th Cir. 2005) (Subpoena Enforcement Matter):

Section 512(a) does not reference the notification provision of $\$ 512(\mathrm{c})(3)(\mathrm{A})$, nor does it contain the remove-or-disable-access provision found in the three safe harbors created for the storage, caching, and linking functions of an ISP. The absence of the remove-or-disable-access provision (and the concomitant notification provision) makes sense where an ISP merely acts as a conduit for infringing material - rather than directly storing, caching, or linking to infringing material-because the ISP has no ability to remove the infringing material from its system or disable access to the infringing material. 
$\S 512(a)$ would apply. Notice in a $\S 512$ (a) context cannot result in "takedown," but it can result in a record of alleged infringers about whom multiple complaints are made. Given $\S 512$ 's requirement that OSPs develop and promulgate a policy for determining "repeat infringers," it seems possible that those who send notices in a peer-topeer context are hoping to create a record that will convince OSPs to terminate users who are the subject of complaints. Anecdotal evidence of correspondence from OSPs to their users in our database shows that some OSPs treat $\S 512$ (a) notices in this way. ${ }^{204}$

The notices in the Chilling Effects database do not, however, uniformly include both OSP communications and complainant communications, so it is difficult to determine what the standard of the field is. A detailed survey of OSPs regarding their practices would be helpful to better map practices in this area.

\section{International Targets}

One surprising result was the large number of notices targeting material that appeared to reside outside the United States, particularly for Google notices (253, or $34 \%$, of the Google notices). Further, a small number of notices (6) were sent to foreign OSPs. While the underlying claim might be strong in the United States, foreign targets may have local defenses; at the very least, foreign governments may look askance at the ex ante takedown process of $\S 512$. Of course, foreign-owned material may be hosted on a United States ISP's server, subject to United States laws. However, the vast majority of these notices are related to Google search index results. For these notices, the material may well reside offshore; Google merely provides a link to the site. This situation raises complex questions related to U.S. jurisdiction over foreign actors who run afoul of United States copyright laws-questions that OSPs are almost certainly not in a position to answer when deciding whether to pull material out of an index. ${ }^{205}$

204. See, e.g., notice \#834, http://chillingeffects.org/dmca512/notice.cgi?NoticelD=834 (dated Sept. 8, 2003) ("[P]lease be advised that should Comcast receive further copyright infringement complaints related to your Comcast Internet account, Comcast may terminate the account. ...").

205. See Yen, supra note 16. See also Jane C. Ginsburg, Copyright Legislation for the "Digital Millennium", 23 COLUM.-VLA J.L. \& ARTS 137, 164 (1999) (discussing how this situation can make it difficult to reach foreign infringers). 


\section{Anti-Circumvention Notices}

Finally, a number of notices-48 §512(c) and $26 \S 512(d)$ notices-specifically request removal of apparent "anticircumvention" devices, or links to anticircumvention devices, under $\S 512$. (An additional five notices did not specifically mention anticircumvention devices, but were possibly targeting them.) We did not add these notices to the count of "substantively flawed" notices. We elected to treat them separately, as they target acts that are likely illegal under $\S 1201$. However, these anticircumvention takedown notices are likely not proper subject matter for $\S 512$ notices at all, ${ }^{206}$ and at the least they pose significant analytic difficulties under $\S 512$.

Of the $\S 512(\mathrm{c})$ notices, 70 notices related to software or computer games, and of those, $48(68.6 \%)$ specifically requested takedown of content based on an anticircumvention claim. Of the remaining 22 notices, five represented possible anticircumvention claims, including game "items" and game "cheats." Thus, of all software and computer game $\S 512(\mathrm{c})$ notices, a total of 53 notices $(76 \%)$ were likely or definitely anticircumvention-related. The anticircumvention claims cited terms such as "cracked copies," "serial numbers or keys," "key generators" and other terms. We note that the term "cracked copies" is vague, and could describe any number of situations: a copy that has been reverse engineered to have the serial number request removed, or to have a serial number embedded in the software, or to have some other change made. Of the $\S 512$ (d) notices, 56 total notices presented software and games claims. Of those notices, $26(46.4 \%)$ presented anticircumvention claims, and 30 $(53.6 \%)$ presented no apparent anticircumvention claims. Some of the notices presented multiple kinds of claims, rendering analysis complex; for instance, claims of distributing works, distributing "hacked" works or various licensing violations (discussed below). Many such notices are form notices that list multiple possible acts, without specifying which is at issue in this instance. The acts may be described vaguely and might specifically reference several acts without specifying which is at issue, including distribution of reverse engineered software, key generator software, software "cheats" or serial numbers and access codes. 207

206. See supra note 98 .

207. See, e.g., notice \#1562, http://chillingeffects.org/dmca512/notice.cgi?NoticelD $=1562$ (dated Dec. 21, 2004) ("[T]he domain listed above ... is offering unlicensed copies of, or is engaged in other unauthorized activities relating to copyrighted computer programs."). See 


\section{Claims Other than Copyright}

A number of notices (193) appear to include claims in addition to, or instead of, copyright infringement-such as unfair competition, trademark-type claims, or privacy concerns. In some instances, a sender may have had a cognizable copyright claim, but they stated concerns beyond or in addition to copyright infringement. For example, as discussed in Section V.E, at least 26 notices reflect strong concerns or details relating to privacy issues.

Licensing restrictions have also been raised by senders unhappy with software resales. Three different senders sent a total of seven cease-and-desist notices to request removal of offers to sell software. Two of the notices sought to remove links to previously authorized resellers. ${ }^{208}$ The other five notices sought to remove links to offers to sell copies of the works; while these may have been illegal copies, the first two notices in the series explicitly reference the sender's "nontransferable license" and state that only the sender or its "authorized distributors or resellers" have the authority to "complete such license transactions or distribute these products." 209 While some licensing restrictions may map to copyright claims, some will not, and most are likely to be enforced via contract law-an area of law not subject to $\S$ 512 takedown or safe harbor. Use of the takedown process to enforce privately-determined rights is a significant expansion, and one that elides the significant policy questions underlying shrink- and clickwrap license enforcement-questions which render an extrajudicial takedown procedure particularly inappropriate. Requests to remove

notice \#1378, http://chillingeffects.org/dmcaS12/notice.cgi?NoticelD=1378 (dated Aug. 4, 2004), regarding the offering a product key; notice $\# 899$,

http://chillingeffects.org/dmca512/notice.cgi?NoticeID=899 (dated Sept. 16, 2003) ("provides access to data that directly violates license agreement and allows our intellectual property to be used illegally ... provides access to illegal serial numbers, 'keygens', patches and copyrighted materials.").

208. Notice \# 1360, http://chillingeffects.org/dmca512/notice.cgi?NoticeID=1360 (dated July 14,2004$)$ complains of an unauthorized reseller. Notice \#813,

http://chillingeffects.org/dmca512/notice.cgi?NoticeID=813 (dated July 24,2003 ) claims that their former reseller is illegally selling their software. This notice was sent from a Czech software company regarding their Slovak reseller, adding international issues to the complexity of the question.

209. Notices \# 940, 1029, 1443, 1477, and 1637, dated from Nov. 3, 2003 to Jan. 17, 2005. Notice \#940 (dated Nov. 3, 2003) and 1029 (dated Dec. 22, 2003) reference the sender's "nontransferable license" and state that only the sender and its "authorized distributors and resellers" have the "authority to complete such license transactions or distribute these products." The other three notices include only the required components of a $\$ 512$ notice. (Notices available by visiting http://chillingeffects.org/dmca512/notice.cgi?NoticeID= followed by the notice \#). 
reverse engineered or adapted software may likewise rely partially or entirely on restrictions imposed by license.

Because $\S 512$ requires OSPs to develop a clear policy and establish a takedown procedure, it seems that senders sometimes shoehorn ill-fitting claims into a copyright complaint in order to obtain relief, a use that is troubling. ${ }^{210}$ Because of the small percentage of notices that reflect any one of these concerns, they are merely anecdotal, but again, add to the picture of how $\S 512$ is being used.

\section{G. Lack of Counter Notification}

A final observation: though the ex ante takedown of questionable material would be troubling under any circumstances, concerns (discussed infra Section VII) about the number of flaws revealed in our data would be somewhat diminished if we had found evidence of counternotices and putback. Only seven counternotices are included in the Chilling Effects dataset, ${ }^{211}$ and very few documented cases of putback can be found. ${ }^{212}$ Confidential conversations with service providers again suggest that our data reflect the overall experience of OSPs, though we obviously cannot draw any conclusions based on the limited notices we have. Here again, further research with OSPs is needed. One possible reason for the low incidence of putbacks is that it is easier for some alleged infringers to move material to another hosting service or web site, rather than accept the 10-14 day

210. See Pierre Leval, Toward a Fair Use Standard, 103 HARV. L. REv. 1105, 1116-19, and note 67 (1990) (Judge Leval, recommending against using copyright to enforce privacy rights, wrote:

Serious distortions will occur if we permit our copyright law to be twisted into the service of privacy interests. First, it will destroy the delicate balance of interests achieved under our privacy law. For example, the judgment that, in the public interest, the privacy right should terminate at death would be overcome by the additional fifty years tacked onto copyright protection.... Moreover, the copyright law is grossly inappropriate to protect privacy and obviously was not fashioned to do so.).

211. Notices \# $360,597,605,912,1048,1186$, and 2371 . (Notices available by visiting http://chillingeffects.org/dmca512/notice.cgi?NoticeID= followed by the notice \#) (notice 2371 available upon request from author).

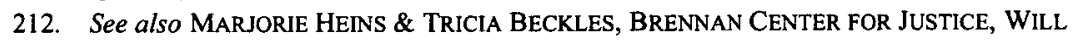
FAIR USE SURVIVE? (2005), available at

http://fepproject.org/policyreports/WillFairUseSurvive.pdf. This report followed up with notice targets, and found that approximately half the targets took material down, regardless of the strength of their claims. The Heins study reviewed all notices (including $\S 512$ notices, but also copyright, trademark and other notices) collected by the Chilling Effects website over the course of one year, and followed up many notices in detail, providing rich anecdotal information about the process. 
takedown. Further, our result may be an artifact of our data, which are so dominated by search index notices. As a search provider has no obligation under $\S 512$ (and generally, no ability) to notify the alleged infringer of takedown, there is little opportunity for targets to use the counternotice process, at all. Google does provide hosting services, and we have a substantial number of $\S 512$ (c) notices from it, but its hosting services are relatively new, and constitute a minority of notices from Google in our data set. Whether counternotices are more common in other hosting situations is a question for further research.

Of the self-reported $\S 512$ (c) notices, relatively few users (only ten) submitted correspondence from the OSP along with the original notice, so there is little opportunity at present to assess whether OSPs are informing their customers of the counternotice procedure. ${ }^{213} \mathrm{We}$ note, however, that of the ten notices from $\S 512(\mathrm{c})$ providers to their customers, four did not provide any information about the counternotice option, ${ }^{214}$ four did, 215 and two were ambiguous or confusing. We have an additional 52 notices where a $\S 512(\mathrm{a})$ provider forwarded information to its client. ${ }^{216}$ Many OSPs bolstered the notices with threats based on the user's obligations from their terms of service; 217 fewer than half (21) presented a $\S 512(\mathrm{c})$-like counternotice option. (We note, however, that of the six universities that were among these OSPs, five proffered counternotice options).

213. We cannot assess from the user-submitted notices without OSP correspondence, whether there was no correspondence from the OSP originally, or whether the user deleted it, possibly because it had personal information or the user deemed it irrelevant.

214. See, e.g., notice \# 2312, http://chillingeffects.org/dmca512/notice.cgi?NoticeID=2312 (available upon request from the author) (AnotheRealm.com notice to customer, noting that they saw nothing infringing, "[h]owever they are asking to have it removed, so please remove the content and let us know when it is done." No information about counternotice procedures was provided.).

215. See, e.g., notice \# 950, http://chillingeffects.org/dmca512/notice.cgi?NoticelD=950 (dated Nov. 13, 2003) (Blogger notice to client with information about counternotice options and a link to a sample counter notice).

216. At least nine other notices in the database are plainly from $\S 512$ (a) OSPs to their customers, but do not include any information from the OSP that could be evaluated.

217. Many large OSPs apparently have a standard counternotification notice in their standard notice to users, but not all. We base this on observations of form language appended to notices forwarded to users by Comcast, Cox, and AT\&T, for example. We observe that the current OSP practices may actually further intimidate users. Many notices include, with information about the counternotice option, a warning that, by filing a counternotice, a target "consents to be sued" in the complainant's jurisdiction. This is true, but this wording may make litigation seem likelier than it is. See MarJorie HeINS \& TRICIA BECKLES, BrenNaN CenTtER FOR JUSTICE, WILL FAIR USE SURVIVE? (2005) (finding that, of targets who filed countemotices or failed to comply with takedown notices, anecdotal reports of litigation or continued pursuit were rare). Additionally, the correspondence we saw fails to explain that countemotices in good faith will not increase legal liability nor increase the likelihood of a finding of liability. 
We expect that there is more to learn from our data set; further, we look forward to investigations into broader data sets, data that relate more closely to hosting services, and the like. Although more research would clearly be useful, we found this data set very helpful in developing a limited picture of $\S 512$ 's use. We discuss our findings and recommend changes in Section VII.

\section{DISCUSSION}

\section{A. Concerns Revealed by the Data}

Copyright infringement on the Internet is a serious issuedistribution of valuable works can occur in a flash, and value may be difficult to recapture - and the idea of a simple, inexpensive process to handle takedowns is a beguiling one. But at what cost comes this benefit? Our data reveal an unfortunately high incidence of questionable uses of the process. Copyright analysis depends on the particular facts and details of the situation. Even a sophisticated and careful sender may send a notice with claims that should be reviewed by a court before the target's material is removed. In many instances, questionable uses may be unintended: deeper investigation of individual notices reveals that some notice senders simply seem not to understand the parameters of copyright law, and why should they? Copyright law is an especially complex, nuanced and fact-specific body of legal rules. A clear, rigid ex ante process such as $\S 512$ seems mismatched with a body of law that derives much of its value from flexibility and nuance.

We were particularly surprised by the findings that such a large number of notices present serious substantive questions about the underlying claim. We expected to see some notices with substantive flaws - the simple ex ante process and the weak remedies available for spurious claims create an irresistible temptation for the upset or unscrupulous. But the high number of problematic notices we found strikes at the heart of the $\S 512$ process and is particularly troubling. At least in our data set, takedown has occurred in numerous questionable situations. Moreover, a large portion of our data was derived from notices to remove links from Google's search index-a situation where liability is not likely to accrue to the OSP, in any case. Flaws in these notices are particularly unlikely to be caught or remedied, as a search engine can rarely notify creators of indexed content that they have been de-listed. Yet removal from search 
engines is in many ways almost as significant to the target as removal from a webhost and the Internet-without search engines, most users have no way to find or access content. The removal of links from search indexes can cause the information essentially to disappear, as it is no longer easily findable. ${ }^{218}$ Flawed removals in the search engine context, therefore, are both unlikely to be caught or fixed, and pose a significant threat to speech interests.

In addition, we observed other issues with the notices in our data set. A number of notices appeared to be addressing a primarily noncopyright concern, whether a competitor's search engine ranking, trademark rights, or personal privacy or other issues. This is also quite troubling, since the debates around the legislation, the compromises made, and the policy decisions enshrined by Congress in $\S 512$ were limited to questions of copyright infringement.219 Additionally, though we cannot draw conclusions based upon the lower number of $\S 512$ (c) "hosted content" notices, these also contained substantive flaws. Finally, the unexpected and unintended use of $\S 512(\mathrm{a})$ in an attempt to police peer-to-peer filesharing creates separate concerns, discussed infra.

Thus, the implications for expression on the Internet of this extrajudicial process appear, from our limited data, significant. Removal of speech from the Internet, with very little or no process, is a strong remedy for allegations of infringement, especially where there are so few recourses available to the targeted speaker. The stakes are high. As the Supreme Court recognized in Reno $v$. $A C L U, 220$ the Internet is a major platform of speech. Its importance to the American public has only grown in the decade since Reno was decided. The Internet is now a primary resource for speakers seeking to disseminate significant business, political, legal, medical, scientific, artistic and creative data. In the realm of political information, the Internet is perhaps the most significant platform for dissemination of unpopular and controversial information. As such, the high incidence

218. See Deborah Fallows, SEARch ENGINE USERS (Pew Research 2005), available at http://www.pewinternet.org/pdfs/PIP_Searchengine_users.pdf. $84 \%$ of Internet users have used search engines; on any given day $56 \%$ of those online use search engines; when searching, $44 \%$ stick to a single search engine; $48 \%$ stick to 2 or 3 ; only $7 \%$ use more than three. Id. at page 13 . The $7 \%$ of users who use more than three search engines are the most sophisticated users; leaving $93 \%$ of users relying on three or fewer search engines. The level of trust and reliability in a particular search engine is therefore particularly important for these users, who constitute the vast majority of Internet searchers.

219. See supra Section IV.

220. Reno v. American Civil Liberties Union, 521 U.S. 844 (1997). 
of flawed notices we discovered in our review gives us pause. Discussion of a few of the particular issues follows.

\section{Confusion Regarding the Coverage and Limits of Copyright Law and Section 512}

As described supra Section VI, our data reveal confusion about the rights conferred both by copyright law, and by the DMCA $\S 512$ process, at least on the part of senders. ${ }^{221}$ Although we did not expect it, in hindsight this is not surprising: copyright law is a complex and nuanced area of law, and the $\S 512$ process is simple and inexpensive for senders. Perhaps such a result is to be expected. Although sending a notice is simple, matching the notice with the proper parameters of the takedown does not always occur. We discussed supra the fact that senders sometimes send notices that reveal a misunderstanding of the subject matter and limits of copyright protection. Senders also sometimes request or demand OSP action other than that required by the DMCA-requesting policing, ${ }^{222}$ affirmations of removal or other communications. It cannot be ascertained from the notices whether this reflects senders' misunderstanding of their rights, bluster on the part of senders or other goals. Further, the demanded removal itself can sometimes be overbroad. ${ }^{223}$ The $\S 512$ process is intended to target only that content which is infringing. In practice, however, users sometimes cite a high-level URL, or a URL that covers a broad range of material, causing, for instance, an entire website to be taken down or delisted, instead of solely the infringing content. ${ }^{224}$ Likewise, a single web page that includes a wide variety of content could be removed, just to get at one incorporated image file, overly-lengthy quotation, etc. 225

221. The low number of counternotices discovered, even in the face of the relatively high number of flaws that we found, see supra Section VI, could indicate a similar confusion on the part of notice targets, but it is impossible to know.

222. See, e.g., notice \# 1934, http://chillingeffects.org/dmca512/notice.cgi?NoticeID=1934 (dated May 12, 2005) (Goldon Fishing).

223. See, e.g., notice \# 433, http://chillingeffects.org/dmca512/notice.cgi?NoticelD $=433$ (dated Oct. 16, 2002) (Leslie Kelly / Amish requesting takedown of the entire NAMI website, because one article on the site had one image taken from a website which took it from his book.

224. See, e.g., notice \# 548 (available upon request from the author) (a Scientology complaint about the Scientology criticism site, "Operation Clambake." In this instance, the targets' website ultimately was put back into Google's search index).

225. See, e.g., notice \# 433, http://chillingeffects.org/dmca512/notice.cgi?NoticeID=433 (dated Oct. 16, 2002) (Leslie Kelly requesting takedown of the National Alliance on Mental Illness (NAMI) website because of the inclusion of one photograph as an illustration on a single web page: "I hereby demand that Cogent Communications effect an immediate takedown of your client's website at http://nami.org until they remove my image...."). 


\section{Competitive Uses of $\S 512$}

The extent of the observed use of $\S 512$ (d) against competitors was also unexpected and possibly troubling. On the one hand, copyright disputes between competitors are to be expected. On the other hand, $64(22.5 \%)$ of competitor-related $\S 512(\mathrm{~d})$ notices sent to Google were substantively questionable. Of the $\S 512$ (d) notices sent to Google we deemed competitor-related, at least $27(9.5 \%)$ specifically mention that they are unhappy with the page rank of the other party. ${ }^{226}$ As such, § 512(d) appears to be used in some instances as a new weapon in the search-rank wars, another worrisome and unintended consequence of the process. As the Internet has become a central marketplace, market participants have cast about for new competitive tools. The $\S 512$ process-simple, cheap and almost always successful in removing the target from a search engine-was too irresistible not to be used. Unfortunately, as with other questionable uses, the defenses and remedies for misuse are not sufficiently robust to forestall actual misuses.

\section{Section 512(a) "Notices"}

Concerns about improper takedown are thrown into relief by the use of $\S 512$ (a) "notices." Based on our limited data-which does not allow us to draw conclusions-we suspect that notices sent in $\S 512$ (a) situations often represent the music and movie industries' attempts to reduce the untrammeled sharing of copyrighted music and movies over peer-to-peer networks. This is further confirmed by a confidential interview with a large-ISP representative, which revealed that larger ISPs received tens-of-thousands of notices-largely § 512(a) complaints-in a year. 227 The cost to ISPs of dealing with this many notices is high, indeed. The potential cost to an accused infringer is also high. If a sender succeeds in convincing an OSP to respond to a $\S 512$ (a) notice as if it were a $\S 512$ (c) or (d) notice, all the OSP can do is terminate the target's service contract. Users suffer the harsh remedy of loss of Internet access, through an extrajudicial process with no guaranteed remedy of return. This remedy goes far

226. As an aside, we note that many of these notices-foremost among them those from Mir Internet Marketing - are from so-called search-engine optimizers, a relatively new industry dedicated to helping website developers increase search engine rank and traffic to their sites. See Brad Stone, Hotwiring Your Search Engine, NEwSwEEK, Dec. 19, 2005, available at http://www.msnbc.msn.com/id/10415455/site/newsweek. If $\S 512$ notices are becoming a front in the search engine ranking wars, then it is perhaps unsurprising that the SEOs use these tactics, themselves.

227. See also supra note 99. 
beyond stopping the user's alleged copyright infringement and entirely removes her ability to obtain Internet-based information or to communicate on any topic through an Internet-based medium through her account, be it a message board, blog commentary or e-mail. Further, in many markets, there are only limited numbers of alternative providers of Internet service. 228 Unfortunately, it is not clear that an offsetting benefit to copyright holders exists. Even if a user's account is terminated, that user is likely only one of many sources of the offending file. And when OSPs afford users little or no procedural opportunity to dispute or respond to claims, senders have no feedback mechanism to improve their own accuracy and targeting methods.

This situation can pose significant due-process-type problems for Internet access subscribers. Deeper analysis of the $\S 512$ (a) notices in our data set reveals that OSPs sometimes threaten to cut off the user's Internet access based solely on the single allegation mentioned in the notice, requiring assurances or proof that the alleged activity has ceased. 229 Similar "infringement activity reports" have generated other litigation on behalf of the recording industry, some of which has been challenged on the grounds of misidentifying the infringing party..$^{230}$ Indeed, one notice in the database includes a note from the target, complaining that they did not in fact make such a distribution; but as the original complaint was not included, they had no way to

228. See Lee Rainie, et al., Pew Internet \& american life Project, Rural areas AND THE INTERNET 10 (2004), available at

http://www.pewinternet.org/pdfs/PIP_Rural_Report.pdf ("About $29 \%$ of rural users say the ISP to which they subscribe is the only one available to them.").

229. See, e.g., notice \#188, http://chillingeffects.org/dmca512/notice.cgi?NoticeID=188 (dated Nov. 5, 2001) ("Failure to comply with these policies may result in a permanent termination of your service... A A reply to this e-mail is required."); notice \#917 http://chillingeffects.org/dmca512/notice.cgi?NoticeID=917 (dated O't. 24, 2003) ("To avoid any possible interruption in service, please notify us of your corrective actions regarding this issue."); notice \# 2200 (dated Aug. 1, 2005) (available upon request from the author) ("Accordingly, Cox will suspend your account and disable your connection to the Internet within 24 hours of your receipt of this e-mail if the offending material is not removed.").

230. See Unsafe Harbors: Abusive DMCA Subpoenas and Takedown Demands, Electronic Frontier Foundation, Sept. 26, 2003, http://www.eff.org/IP/P2P/20030926_unsafe_harbors.php (describing multiple misidentifications by the Recording Industry Association of America in its subpoenas and complaints); Jordana Boag, The Battle of Piracy Versus Privacy: How the Recording Industry Association of America (RIAA) Is Using the Digital Millennium Copyright Act (DMCA) As Its Weapon Against Internet Users' Privacy Rights, 41 CAL. W. L. REV. 24 (2004) (describing some of the misfilings); and Lauren McBrayer, The DirecTV Cases: Applying Anti-SLAPP Laws to Copyright Protection Cease-and-Desist Letters, 20 BERKELEY TECH. L.J. 603 (2005) (explaining how DMCA enforcement companies use bots to find potentially infringing files, and describing some of the problems that can and have ensued as a result of mis-identification by those bots). 
protest it. ${ }^{231}$ Universities receiving such notices have initiated disciplinary proceedings against students, including in one instance reporting to a law student's dean allegations that the student downloaded gay pornography. 232 We also observed some obvious misstatements of the law in the notices from OSPs to their subscribers. For instance, some notices represented to the targets that the OSP was covered under the provisions of $\S 512(\mathrm{c}){ }^{233}$

Last but not least, the use of "takedown notices" in contexts where $\S 512$ (a) would apply seems to indicate that the process is not working for some copyright holders. Peer-to-peer and other distributed networks were not anticipated by policymakers during the crafting of $\S 512$, and in a world where valuable copyright properties are distributed without "hosting" ever occurring, the notice-and-

231. Notice \# 2230 (dated July 18, 2005; unpublished but archived at Chilling Effects). On submitting the notice to Chilling Effects, the target wrote:

IMPORTANT NOTE: There was NO attachment included with this e-mail notice. Therefore we do not know the identity of complaintant [sic], what material allegedly "infringes the copyrights of a complainant's members". I replied asking for more information, at least a copy of the complaint. No response from the ISP as of this submission, and our account has not been disabled (yet?). I would like to know what we should do if Cox were to decide to disable our account, since Cox has a MONOPOLY on cable internet in Nevada. If we lost our account, my husband and I will be without Internet! We are both (and have always been) hard-working, law abiding citizens and would NEVER knowingly infringe on someone's copyrights. HELP!

232. Notice \# 837, http://chillingeffects.org/dmca512/notice.cgi?NoticeID=837 (dated Sept. 3, 2003) (notice was "forwarded to Student Judicial Affairs for further investigation/action" and the e-mail was cc'd to the Associate Dean of the Law School).

233. See, e.g., notice \# 2200 (available upon request from the author) (dated Aug. 1, 2005): [W]e have received a notification that you are using your Cox High Speed Internet service to post or transmit material that infringes the copyrights.... Pursuant to the provisions of the [DMCA], .. Cox is required to 'act expeditiously to remove, or disable access to' the infringing material in order to avoid liability for any alleged copyright infringement.

In fact, as discussed in Section II, Cox in this instance is acting as a broadband provider, and receives a straightforward safe harbor under $\$ 512(\mathrm{a})$. Cox is not required to "remove or disable access" to the material; that is a requirement imposed on $\$ 512(\mathrm{c})$ providers. Similar misstatements have cropped up elsewhere in the database. In notice \# 627 (available upon request from the author) (dated Mar. 26, 2003) (unpublished for other reasons but on file at Chilling Effects), the OSP sent a notice to its customer stating that, "The purpose of this letter is to allow you to voluntarily remove the content.... If you choose not to remove the DMCA content, Affinity is required to disable access to it... Under the terms of the DMCA, you do not have the right, at this point, to dispute the claims set out in the DMCA notice." The DMCA does not specify when the counternotice could be filed. The statute does contemplate that content will be removed on demand and not replaced until 10-14 days after the counternotice is filed unless the original complainant files litigation. But it is by no means clear that the terms of the statute do not permit counternotice or require that the 10-14 day clock only begin tolling after takedown. 
takedown provisions under $\S 512$ (c) seem less likely to be of use to the very copyright industry groups that helped compromise on the question of OSP liability during the legislative process. Given the costs imposed on OSPs and end users by attempts to make $\S 512(\mathrm{a})$ providers fit into the $\S 512$ (c) mold, we find this result, particularly, to indicate a need for change in the law.

\section{General}

Policy concerns related to questionable takedowns seem likely to increase in importance-however successful or problematic the process is, as the total number of notices sent over time rises, problematic notices may receive attention. Some notices are certainly sent in order to accomplish the paradigmatic goal of $\S 512$-the inexpensive takedown of clearly infringing hosted content or links to infringing web sites. But our data also show the process commonly being used for other purposes: to create leverage in a competitive marketplace, to protect rights not given by copyright (or perhaps any other law), and to stifle criticism, commentary and fair use. These unanticipated or unintended uses of the process are having a continuous and perhaps unquantifiable effect on public discourse. OSPs have significant financial disincentive to attempt to distinguish between spurious and valid copyright claims. Doing a more detailed and costly check on notices would often simply result in an assessment of risk of secondary liability in a "gray" situationexactly what OSPs hoped to avoid through legal safe harbors. In theory, such OSP behaviors might become a consumer choice-point, with consumers choosing OSPs more likely to resist overbroad takedowns, but the lack of public discussion of this issue suggests that consumers have little awareness of the issue or means to compare OSP behavior on this issue. Moreover, search engines, specifically, are not providers chosen by the beneficiaries of their service, and a target generally cannot simply recapture the value of a Googleindexed link by relying on another provider. Neither obvious legal nor marketplace mechanisms operate to check the growth in scope and breadth of what can be placed in a $\S 512$ notice. The simple process and the strong extrajudicial remedy provide a simple and expedient process available to victims and abusers alike, encouraging complainants to shoehorn a variety of ill-fitting claims into copyright.

The surprising number of questionable takedowns we observed, taken in conjunction with the ex ante removal of content, the minimal remedies for abuse of the process, and the apparent lack of use of the counternotice procedures, suggest that few are well-served by the 
current $\S 512$ process, and some or many individuals, as well as public discourse and the Internet's value as an expressive platform, may be harmed. Our dataset is, as noted, limited, so further research to prove or disprove these concerns is necessary. Further research might also help illuminate reforms other than those we suggest in the next section, or help to indicate which among them would be most effective.

\section{B. Suggestions for Change}

The troubling uses of $\S 512$ reveal, we think, a need for reform. In light of the significant flaws apparent in the structure of the act, and in its performance as indicated by this study, some might recommend wholesale repeal of $\S 512$ in favor of a strong universal safe harbor for OSPs. We suspect that such a repeal is unlikely. We therefore suggest some reforms that would return some balance to the present ex ante, extrajudicial takedown system. Moreover, while there are significant problems with the procedure as currently defined, we recognize that the story has not been all bad. ${ }^{234}$ For example, despite abuses by some of their number, some individual copyright holders and small businesses currently benefit from the ease and inexpensiveness of the process. ${ }^{235}$ Therefore, retaining essential benefits for complainants, while increasing protections for targets, is our goal with these suggestions.

First, the ex ante takedown in the $\S 512(\mathrm{c})$ context, combined with lack of counternotice use and other procedural defects, is the feature of the system that strikes the greatest blow to due process and fairness. Therefore, we suggest delaying the takedown until after an opportunity for counternotice has been offered. The drawback to this suggestion is that the complainant would not get the nearly-immediate

234. In fact, one commentator feels the process should be reformed in the other direction, and that even the simple notice process currently available is too onerous a duty for small and independent copyright-holders, who are burdened by policing their own copyrights. He recommends requiring OSPs to police their networks, in part on keyword searches. Colin Folawn, Neighborhood Watch: The Negation of Rights Caused by the Notice Requirement in Copyright Enforcement Under the Digital Millennium Copyright Act, 26 SEATTLE UNIV. L.R. 979 (2003). In light of the numerous demonstrated problems with keyword filtering, we think such a solution would be ineffective, as well as difficult to define, and unnecessarily burdensome on OSPs.

235. Expense is likely a key issue for small copyright holders. Mark Lemley and Tony Reese have suggested that, at least in the P2P context, a UDRP-like system might effectively and inexpensively allow resolution of copyright disputes. While acknowledging the flaws of the UDRP, they suggest that these flaws could be addressed in developing a P2P dispute resolution system. Mark A. Lemley \& R. Anthony Reese, A Quick and Inexpensive System for Resolving Peer-to-Peer Copyright Disputes, 23 CARDOZO ARTS \& ENT. L.J. 1 (2005). 
resolution of a copyright infringement problem that she does now. In light of the substantial number of notices where judicial review is clearly necessary in our dataset, however, it seems that the shift to ex ante takedown created myriad unintended consequences that must be addressed. Building some due process back into the system is necessary. The process would still be simple and inexpensive, and could work relatively quickly.

We additionally suggest some further procedural guarantees and protections. First, we recommend that $\S 512$ (g) be reformed to straightforwardly require OSPs to provide notice to their subscribers before takedown, ${ }^{236}$ and to explicitly disallow undermining this consumer protection through service contracts. Second, requiring some guarantee that the target actually receive the notice would ensure that targets are not surprised by takedowns. ${ }^{237}$ Third, we suggest shifting the putback provision to require OSPs to return any content removed, on receipt of a counternotice filed at any point prior to a judicial settlement of the issue finding against the target. We realize that this weakens the cost-benefit of the $\S 512$ process considerably. After all, however, in the offline world, a cease-anddesist letter should be backed up by a credible threat of litigation. Presumably, the complainant could directly communicate with the target once the OSP has connected them, and negotiations could commence.

We further suggest strengthening the $\S 512$ (f) defense, a reform aimed at ensuring that the notice-and-takedown process is not a tactical tool for the search engine ranking wars, and lessening its use for spurious or frivolous claims. ${ }^{238}$ The $\S 512(\mathrm{f})$ defense requires a

236. Mark Robins points out that the counternotification procedures apply only when OSPs receive notices, not when OSPs $_{s}$ obtain "red flag" knowledge. Mark D. Robins, Digital Millennium Copyright Act Defenses for Providers of Online Storage Services and Information Location Tools, 16 No. 6/7 COMPUTER LAWYER (June/July 1999). We suggest that notice to subscribers would be appropriate in almost all instances of red flag knowledge. An OSP may not be well-suited to assess various defenses a user might have, including first sale, or fair use purpose, or whether a work is substantially similar to another work. Providing notice to the user permits the user to explain the situation if possible, and in the case of inadvertent infringements or infringements due to misunderstandings of the law, take remedial actions themselves. An OSP that wishes to engage in policing the material itself, without notice to the user, ought properly to take on the legal responsibility for harm to the user in wrongful removals.

237. For instance, implementing a "return receipt requested" tag on the e-mailed notices; or at the very least, ensuring that messages are not bounced back from erroneous e-mail addresses.

238. Lauren McBrayer recently reviewed four anti-circumvention cases in which ceaseand-desist recipients filed anti-SLAPP claims against the complainant, DirecTV. Lauren McBrayer, The DirecTV Cases: Applying Anti-SLAPP Laws to Copyright Protection Cease-andDesist Letters, 20 BERKELEY TECH. L.J. 603 (2005). While anti-SLAPP laws offer an interesting 
"material misrepresentation"-a high bar. Coupled with this high bar, the ease and simplicity of the notice-and-takedown process does little to discourage frivolous or ill-thought claims. Thus, we recommend at least strengthening the remedies for abuses of this process. For example, a "material misrepresentation" should entitle the victim to punitive, as well as actual, damages and attorneys' fees.

Finally, we recommend one additional procedural protection for targets. Section 512 should also be amended to clarify that "multiple infringers" are those individuals adjudicated to be infringing in multiple, separate judicial actions. Multiple allegations of infringement ought not count, and this should be clear in the statute. 239

Second, we feel that the scope and structure of $\S 512$ needs significant reform. Section 512 (d) might safely be repealed entirely in favor of a blanket safe harbor, similar to that provided to routing and transmission OSPs under $\S 512(a) .240$ The value of the safe harbor to search engines and indexes is speculative at best, since a search engine's liability for automatically indexed content is attenuated.241 Clarifying any uncertainty here with a straightforward safe harbor for search engines simply makes sense. Repealing the notice-andtakedown process for $\S 512$ (d) providers would not diminish the ability of copyright-holders to target OSPs with closer relationships to providers of infringing content, such as webhosts. And for innocent targets, repeal would solve a problem that is otherwise almost impossible to fix. Removal from a search engine is a nearly

potential response for beleaguered notice recipients, as does the Relate $v$. Jones notion of enjoining parties from filing takedown notices, we feel that these uses of judicial processes to regulate the extrajudicial processes only further demonstrate the need to directly tackle the underlying problem. Relate v. Jones, supra note 195.

239. Malla Pollack likewise recommended that ISPs should only be permitted to disconnect individuals "who have been held repeat infringers by a court." Malla Pollack, Rebalancing Section 512 to Protect Fair Users from Herds of Mice-Trampling Elephants, or A Little Due Process Is Not Such a Dangerous Thing, 22 SANTA ClaRA COMPUTER \& HIGH TECH. L.J. 547, 574 (2006).

240. We are certainly not the first to suggest this more limited reform. See also Craig W. Walker, Application of the DMCA Safe Harbor Provisions to Search Engines, 9 VA. J.L. \& TECH. 1185 (2004) (arguing that it would be better to simply exempt search engines altogether from liability, because bad statutory drafting in $\S 512$ makes the statute difficult to parse, targeting search engines poses threats to free expression, and copyright owners have other means to protect their interests).

241. Section 512(d) may currently provide some benefit to ISPs by heightening the test for secondary liability. See Yen, supra note 16; Mark A. Lemley \& R. Anthony Reese, Reducing Digital Copyright Infringement Without Restricting Innovation, 56 STAN. L. REV. 1345 (2004). It would be better to simply clarify that mere linking constitutes neither contributory infringement, vicarious liability, nor "inducement" to infringe. 
irremediable harm, since those whose links are removed rarely receive notice. Such a repeal would also satisfactorily harmonize and ratify the growing consensus in caselaw that linking, by itself, does not constitute direct or secondary infringement. Finally, it would remove any temptation to send flawed notices in an attempt to influence one's search index rank by removing a competitor.

In light of Blake A. Field v. Google, we recommend clarifying the plain language of $\S 512$ (b) to make it clear that any automatic caching of content subordinate to indexing processes or network management would be covered by a straightforward safe harbor. While the "notice-and-takedown" provision for password-protected content seems like a good idea, it also seems unnecessary and overly technical, and thus likely to cause confusion. We recommend further study into whether this provision is used, and how-and perhaps a wait-and-see approach to give courts an opportunity to adopt or reject the Blake court's application of it. If it is consistently unused or misapplied, then $\S 512$ (b) might safely be repealed.

Recognizing that significant file-sharing and copyrightinfringing behavior has shifted from the $\S 512$ (c) and (d) environment to the $\S 512(\mathrm{a})$ environment, where the notice-and-takedown procedures are ineffective, but widely implemented, we recommend Congress evaluate ways to provide compensation for copyright holders for unauthorized file-sharing. 242 We do not recommend implementation of a notice-and-takedown process in the $\S 512(\mathrm{a})$ environment. Given the evidence of overbroad use in the $\S 512(\mathrm{c})$ and (d) contexts, we anticipate that similar problems will arise in the $\S 512$ (a) context. Such problems would perhaps be more serious in the $\S 512(\mathrm{a})$ context, as "routing and transmission" services are the means through which speakers access the essential communications platform that is the Internet. Moreover, evidence of mistaken targeting in the existing P2P litigation ${ }^{243}$ makes us leery of any stateauthorized restrictions on such an important function without robust procedural protections.

242. Should Congress accept this invitation, it will have myriad recommended courses of action to evaluate. Neil W. Netanel, Impose a Noncommercial Use Levy to Allow P2P File Sharing, 17 HARV. J.L. \& TECH. 1, available at http://ssm.com/abstract=468180; WILLIAM Fisher, PROMISES TO KEEP: TECHNOLOGY, LAW, AND THE FUTURE OF ENTERTAINMENT (Stanford Univ. Press 2004); A BETTER WAY FORWARD: VolUNTARY COLlECTIVE LICENSING OF MUSIC FILE SHARING (Electronic Frontier Foundation 2004),

http://www.eff.org/share/collective_lic_wp.php.

243. See supra note 229. 
However, if, as we understand, vast numbers of copyright infringement notices are sent to $\S 512$ (a) OSPs, then this provision needs reform as well. As previously stated, we do not recommend any notice-and-takedown provisions for the $\S 512$ (a) context. However, it seems that at least some service providers do act on notices, whether by building a record of multiple accusations on their users, or by threatening their users with cut-off based on Terms of Service violations. Consequently, in light of the serious speech and livelihood interests at stake, we recommend that $\S 512$ (a) OSPs be required to inform their users of any complaints against them, and that users be offered the opportunity to submit counternotices in advance of any action taken against them. The procedural protections we recommend affording to $\S 512(\mathrm{c})$ notice targets should also be applied by any $\S 512$ (a) OSP that implements a notice, recordkeeping or cut-off process-specifically, a robust notice requirement; guarantee of receipt of notice; and reinstatement of service on receipt of counternotice at any point unless a court finds against the target. Additionally, section 512(f) protections against abuse should be afforded to $\S 512(a)$ subscribers.

\section{CONCLUSION}

Other reforms than those sketched here may be in order, particularly with respect to $\S 512(\mathrm{c}) .{ }^{244}$ However, the reforms we

244. Participants at the Santa Clara Conference made some additional suggestions. Eric Goldman, Marquette University, raised the notion of trying to separate high commercial value copyrights from low commercial value copyrights. This idea strives to capture the important distinction between commercial piracy of commercially valuable copyrighted works and personal and fair uses. This is an important distinction, and one that is certainly elided by the process as it exists now. However, we fear that it would be difficult to define, difficult for users to understand, and difficult for OSPs to implement of it without significant reviews of the notices. Moreover, we see no justification for valuing the copyrights of large rightsholder industries more than the copyrights of small and independent rights' holders whose copyrights may be objectively less commercially valuable. We therefore do not recommend such a distinction at this time. Likewise, Malla Pollack suggested regulating uses differentially. See Malla Pollack, Rebalancing Section 512 to Protect Fair Users from Herds of Mice-Trampling Elephants, or A Little Due Process Is Not Such a Dangerous Thing, 22 SANTA CLARA COMPUTER \& HIGH TECH. L.J. 547 (2006). For instance, personal uses would not be subject to the notice-and-takedown provisions while commercial uses would be. This would set up a separate set of standards used only to evaluate online uses of copyrighted content, which would ultimately create more confusion in the law. We therefore recommend targeting the $\S 512$ process directly. Moreover, while protecting personal noncommercial uses would certainly address many problems with the $\S 512$ process, such a reform could also address many problems endemic to copyright law more generally.

The literature on $\S 512$ has yielded some jurisprudential recommendations over the years. Bretan recommended that courts examine the safe harbor question prior to any question of 
propose would go some way toward re-balancing the $\S 512$ framework to protect copyright holders, while hopefully avoiding unduly burdening OSPs, and reinstating some critical procedural protections for alleged infringers. We look forward to further research into how the process is being used in hopes that that research will further support these suggestions or suggest better alternatives. Section 512 was developed with good intentions to solve a difficult problem, and though our data lead us to think its critics' concerns were well-founded, we hope that some wise adjustments will address those concerns.

liability, since reviewing liability issues first may color the analysis of the safe harbor. Jennifer Bretan, Harboring Doubts About the Efficacy of $\$ 512$ Immunity Under the DMCA, 18 BERKELEY TECH. L.J. 43 (2003). We note that in many instances, it would also be judicially more efficient to review safe harbor first. Some courts seem to agree. See, e.g., Corbis v. Amazon.com, 351 F. Supp. 2d at 1097 ("Although it may seem premature to address Amazon's DMCA defense before first determining whether Amazon has violated Corbis's copyrights. ... such an approach makes sense under the circumstances."). 
